\title{
On new solvatomorphs of the metalloligand [Ni(o-van-en)]
}

\author{
Anna Vráblová,, ${ }^{a, c, d}$ Milagros Tomás ${ }^{\text {b }}$, Ján Titiš,,${ }^{\mathrm{e}}$ Juraj Černák ${ }^{\text {a }}$, Larry R. Falvello ${ }^{\text {c* }}$ \\ ${ }^{a}$ Department of Inorganic Chemistry, Faculty of Sciences, P. J. Šafárik University in Košice, \\ Moyzesova 11, 04154 Košice, Slovakia \\ ${ }^{b}$ Instituto de Síntesis Quimica y Catálisis Homogénea (ISQCH), Departamento de Química \\ Inorgánica, Pedro Cerbuna 12, University of Zaragoza-CSIC, E-50009 Zaragoza, Spain \\ ${ }^{c}$ Departamento de Química Inorgánica, Instituto de Ciencia de Materiales de Aragón (ICMA), \\ University of Zaragoza-CSIC, Pedro Cerbuna 12, E-50009 Zaragoza, Spain \\ ${ }^{d}$ Department of Chemical Theory of Drugs, Faculty of Pharmacy, Comenius University in \\ Bratislava, Odbojárov 10, 83232 Bratislava, Slovakia \\ ${ }^{e}$ Department of Chemistry, FPV, University of SS Cyril and Methodius, , nám. J. Herdu 2, \\ 91701 Trnava, Slovakia.
}

Correspondence e-mail: falvello@unizar.es

\begin{abstract}
The Schiff-base bis-(2-hydroxy-3-methoxybenzylidene)ethylenediamine, denoted $\mathrm{H}_{2}$ (o-vanen), is a versatile two-compartment polydentate ligand that can bring different guests, such as a transition metal and a lanthanoid, into close proximity to produce novel complexes with potentially singular properties. The base, which is prepared by the condensation of $o$-vanillin with ethylenediamine, reacts with nickel(II) carbonate to yield a microcrystalline product which upon recrystallization from acetone, ethanol and isopropanol, yielded three solvatomorphs of $[\mathrm{Ni}(o$-van-en $)]$. These products, the hydrate $[\mathrm{Ni}($ o-van-en $)] \cdot n \mathrm{H}_{2} \mathrm{O}(n=1.16, \mathbf{1})$, the ethanolwater solvate $[\mathrm{Ni}(o$-van-en $)] \cdot \mathrm{H}_{2} \mathrm{O} \cdot \mathrm{EtOH}(2)$ and the isopropanol-water solvate [Ni(o-vanen) $] \cdot \mathrm{H}_{2} \mathrm{O} \cdot i \mathrm{PrOH}(3)$, all contain the molecular complex [Ni(o-van-en)], as characterized by single-crystal x-ray diffraction. The $[\mathrm{Ni}(o-v a n-e n)]$ fragment, which has been developed as a metalloligand for the preparation of mixed-metal ( $\mathrm{Tr}-\mathrm{Ln})$ complexes with novel magnetic properties, here forms solvatomorphs whose crystals display pronounced differences in morphology and stability. The Ni(II) center in each of the three solvatomorphs is coordinated by the (o-van-en $)^{2-}$ ligand in a square geometry with a $c i s-\mathrm{N}_{2} \mathrm{O}_{2}$ donor set. Each solvatomorph contains water solvate molecules; and in addition, ethanol and isopropanol solvate molecules are present in $\mathbf{2}$ and $\mathbf{3}$, respectively. Full Interaction Maps were used for comparison of the intermolecular interactions, by way of understanding the factors leading to the different solvation behavior. A review of the known structures containing o-van-en fragments is used as a contextual backdrop for a discussion of the new solvatomorph structures. Calculations based
\end{abstract}


on an energy-decomposition model are used to characterize the interactions within dimeric aggregates observed in the structures of $\mathbf{2}$ and $\mathbf{3}$.

Keywords: Ni(II) complex, metalloligand, crystal structure, solvate molecules, Schiff base, thermal properties

\section{Introduction}

The long-familiar position of single-crystal x-ray structure analysis as the sine qua non front-line technique for characterizing coordination compounds (and others) has spawned a number of derivative endeavors for obtaining molecular crystals, characterizing their physical properties and even attempting to design crystals with specific properties particular to the molecular crystalline state and aimed at specific applications. As is well known, recrystallization from a host of different solvents is one of the common approaches to obtaining adequate crystals, as solvent molecules can act as coformers, completing a pattern of molecules and non-covalent interactions that the principal molecule alone may not be capable of forming. As a result, the study of solvates themselves has been considered valuable in the larger context of obtaining and characterizing useful crystalline samples of molecules with targeted structural and/or physical properties [1]. Besides the obvious interest in understanding the formation of solvated crystals [2], the existence of such solvates can thus have important practical implications for other fields, including magnetism [3-5], pharmacy [6-9], agrochemicals, energetic materials and others [10].

Within our broader study of magnetically active complexes, we have prepared the complex [Ni(o-van-en $)]$. [ $\mathrm{H}_{2}($ o-van-en $)$ is the Schiff base bis-(2-hydroxy-3-methoxybenzylidene)ethylenediamine, Scheme 1],

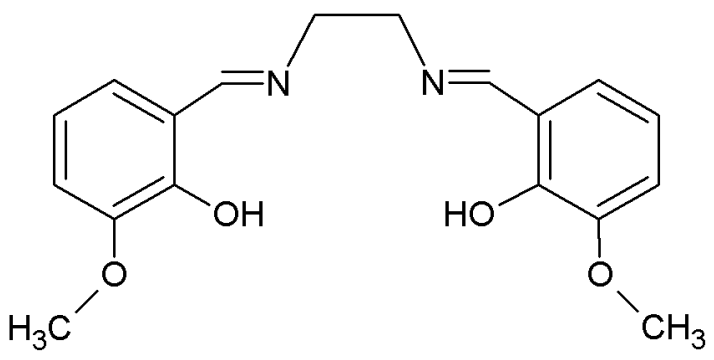

Scheme 1. Structure of $\mathrm{H}_{2}(o-v a n-e n)$ 
intended as a building block for the preparation of magnetically active bimetallic Ni-Ln complexes ( $\mathrm{Ln}=$ lanthanoids) [11]; the rationale for this approach has been described in the literature [12-14]. Briefly, the transition-metal complex of the deprotonated Schiff base acts as a metalloligand capable of further incorporating a lanthanoid center in the outer cavity to yield a heterobimetallic (Tr-Ln) system with intriguing properties. With just the transition metal present, we find that the outer coordination cavity acquires a different function. During recrystallization of the crude microcrystalline product obtained by the reaction of nickel(II) carbonate with the free Schiff base $\mathrm{H}_{2}(o-v a n-e n)$, we observed the formation of three distinct solvatomorphs of the neutral complex $[\mathrm{Ni}($ o-van-en $)]$; we report here the syntheses, characterization and low temperature crystal structures including detailed characterization of the supramolecular structures. Pronounced differences in crystal morphology pertain; these serve as an experimental demonstration of the influence of the solvate shape, size and location on the shape and stability of the resulting crystals. The three new solvatomorphs are further compared with previously reported solvatomorphs with chloroform and dimethylformamide $[15,16]$, along with the room temperature structure of $[\mathrm{Ni}(o-v a n-e n)] \cdot n \mathrm{H}_{2} \mathrm{O},(n=1)[17]$.

\section{Experimental}

\subsection{Materials}

Nickel(II) carbonate, $\mathrm{NiCO}_{3}, o$-vanillin, ethylenediamine, ethanol, acetone and isopropanol were purchased from commercial sources and used as received.

\subsection{Synthesis of the ligand $\mathrm{H}_{2}$ (o-van-en)}

For the synthesis of $\mathrm{H}_{2}$ (o-van-en) a modification of a previously reported method [18] was used. Ethylenediamine $(0.1 \mathrm{ml}, 1.5 \mathrm{mmol})$ was added to $50 \mathrm{ml}$ of an ethanolic solution of $o$-vanillin (0.4542 g, $3 \mathrm{mmol})$. The mixture was placed in a boiling flask and refluxed for 3 hours. The final solution was filtered and left for crystallization. After a few hours dark yellow crystals of the product appeared. The crude product was filtered and washed with $2 \mathrm{ml}$ of diethylether. Yield: $90 \%$. Purity and identity of the product were confirmed by CHN analysis, IR, UV-Vis, ${ }^{1} \mathrm{H}$ and ${ }^{13} \mathrm{C}$ NMR spectroscopies and by measuring the melting point.

Anal. [\%], calculated for $\mathrm{C}_{18} \mathrm{H}_{20} \mathrm{O}_{4} \mathrm{~N}_{2}: \mathrm{C}, 65.83 ; \mathrm{H}, 6.15 ; \mathrm{N}, 8.53$; found: $\mathrm{C}, 66.30 ; \mathrm{H}, 6.33 ; \mathrm{N}$, 8.57 . 
IR $\left(\mathrm{cm}^{-1}\right)$ of $\mathrm{H}_{2}$ (o-van-en): 3746w, 2997w, 2931w, 2848w, 1631s, 1463s, 1438m, 1408m, $1325 \mathrm{w}, 1295 \mathrm{w}, 1246 \mathrm{vs}, 1189 \mathrm{~m}, 1170 \mathrm{~m}, 1133 \mathrm{~m}, 1080 \mathrm{~s}, 1054 \mathrm{~m}, 1010 \mathrm{~m}, 987 \mathrm{~m}, 962 \mathrm{~s}, 836 \mathrm{~s}$, $791 \mathrm{~s}, 782 \mathrm{~s}, 740 \mathrm{~s}, 729 \mathrm{~s}, 620 \mathrm{~m}, 521 \mathrm{~m}, 441 \mathrm{~m}$.

UV-Vis (nm) in EtOH: 219, 264; in $\mathrm{CHCl}_{3}: 265,334$.

${ }^{1} \mathrm{H}-\mathrm{NMR}: 3.92 \mathrm{~m}, 6.84 \mathrm{~m}, 7.267 \mathrm{~s}, 8.323 \mathrm{~s}, 13.5 \mathrm{~s}$, b.

${ }^{13}$ C-NMR: 56.056, 59.467, 114.084, 118.032, 118.419, 123.149, 148.269, 151.402, 166.643.

Melting point: $162.5^{\circ} \mathrm{C}\left(165^{\circ} \mathrm{C}\right.$ reported [18]).

\subsection{Synthesis of complexes}

\subsection{1 [ $\mathrm{Ni}(o-v a n-e n)] \cdot n \mathrm{H}_{2} \mathrm{O}(n=1.17, \mathbf{1})$}

Solid $\mathrm{H}_{2}$ (o-van-en) (2 g, $\left.6 \mathrm{mmol}\right)$ and nickel(II) carbonate $(0.7 \mathrm{~g}, 6 \mathrm{mmol})$ were added to 100 $\mathrm{ml}$ of water and heated in an open beaker. After one hour of reaction the resulting brown microcrystalline product was separated by filtration, washed with $2 \mathrm{ml}$ of ethanol and dried in air. Yield: $79 \%$.

Anal. [\%], calculated for $\mathrm{C}_{18} \mathrm{H}_{20} \mathrm{O}_{5} \mathrm{~N}_{2} \mathrm{Ni} \cdot n \mathrm{H}_{2} \mathrm{O}$ with $n=1.5$ (full occupancy of atom O6): $\mathrm{C}$, 52.46; H, 5.14; N, 6.80; found: C, 52.14; H, 4.79; N, 6.54; calculated with $n=1.17$ from X-ray single crystal analysis: C, 53.27; H, 5.04; N, 6.90 .

IR (cm $\left.{ }^{-1}\right)$ : 3454b, 3055w, 2934w, 2835w, 1621s, 1602s, 1547m, 1472s, 1447s, 1392w, 1314s, $1232 \mathrm{~s}, 1167 \mathrm{~m}, 1109 \mathrm{~m}, 1092 \mathrm{~m}, 1080 \mathrm{~m}, 1001 \mathrm{~m}, 973 \mathrm{~m}, 860 \mathrm{~m}, 777 \mathrm{w}, 722 \mathrm{~s}, 662 \mathrm{w}, 619 \mathrm{~m}, 571 \mathrm{w}$, $543 \mathrm{w}, 480 \mathrm{~m}, 426 \mathrm{~m}, 401 \mathrm{~m}$.

Single crystals suitable for X-ray data collection were obtained by dissolving the microcrystalline product in acetone; when left overnight the resulting clear solution yielded a garnet red crystalline product $\mathbf{1}$.

\subsection{2 [Ni(o-van-en $)] \cdot \mathrm{H}_{2} \mathrm{O} \cdot \mathrm{EtOH}(2)$}

Single crystals of complex $\mathbf{2}$ were obtained by the same procedure as was used for complex $\mathbf{1}$, with the difference that the crude product was recrystallized from ethanol. After dissolving the crude product a clear solution was obtained which overnight yielded red prisms of 2 exhibiting low stability on standing in air. The crystals were used for single crystal X-ray analysis and for measuring the IR spectrum immediately after harvesting them from the mother liquor.

IR ( $\left.\mathrm{cm}^{-1}\right)$ : 3446b, 3055w, 2934w, 2834w, 1621s, 1602s, 1547m, 1471s, 1447s, 1392w, 1313s, $1232 \mathrm{~s}, 1167 \mathrm{~m}, 1109 \mathrm{~m}, 1079 \mathrm{~s}, 1000 \mathrm{~m}, 973 \mathrm{~m}, 859 \mathrm{~m}, 777 \mathrm{w}, 722 \mathrm{~s}, 667 \mathrm{w}, 619 \mathrm{~m}, 571 \mathrm{w}, 542 \mathrm{w}$, 480m, 425m, 401s.

\subsection{3 [Ni(o-van-en $)] \cdot \mathrm{H}_{2} \mathrm{O} \cdot i \operatorname{PrOH}(3)$}


Single crystals of complex $\mathbf{3}$ were obtained by the same procedure as was used for complex $\mathbf{1}$, with the difference that the crude product was recrystallized from isopropanol. Single crystals of $\mathbf{3}$, in the form of tiny brown needles, separated overnight and were filtered, washed quickly with a small portion of cold isopropanol and dried in air.

IR $\left(\mathrm{cm}^{-1}\right)$ : 3508w, 3478w, 3330w, 3056w, 2961w, 2937w, 2840w, 1621s, 1603s, 1548m, 1473s, $1449 \mathrm{~s}, 1408 \mathrm{~m}, 1335 \mathrm{w}, 1314 \mathrm{~s}, 1243 \mathrm{~s}, 1232 \mathrm{~s}, 1168 \mathrm{~m}, 1136 \mathrm{w}, 1108 \mathrm{~m}, 1080 \mathrm{~s}, 1000 \mathrm{~m}, 972 \mathrm{~m}$, $958 \mathrm{~m}, 893 \mathrm{w}, 858 \mathrm{~m}, 820 \mathrm{w}, 782 \mathrm{w}, 727 \mathrm{~s}, 660 \mathrm{w}, 620 \mathrm{~m}, 572 \mathrm{w}, 542 \mathrm{w}, 480 \mathrm{~m}, 463 \mathrm{w}, 425 \mathrm{~m}, 400 \mathrm{~s}$.

\subsection{Physical measurements}

$\mathrm{CHN}$ analyses were performed on an Elemental Analyzer vario MICRO instrument. Infrared spectra were recorded in the range of $4000-400 \mathrm{~cm}^{-1}$ on a Nicolet 6700 FT-IR spectrometer using the ATR technique and with a Smart Orbit attachment. The temperature-dependent FTIR spectra of 1 were measured from a KBr pellet on the same instrument using a Smart Proteus (Thermo Scientific) heating device. X-ray powder diffraction patterns were recorded on a RIGAKU D-Max/2500 diffractometer with rotating anode and RINT2000 vertical goniometer, in the $2 \theta$ range $7-50^{\circ}$ using $\mathrm{Cu} \mathrm{K} \alpha_{1,2}$ radiation $(\lambda=1.54178 \AA)$. The calculated patterns were obtained using the program Mercury CSD 3.1.1 Development [19]. The measured powder diffraction pattern was fitted by the LeBail method [20] using the program JANA2006 [21].

Thermal properties were studied using a 2960 SDT TA instrument under the following conditions: sample weight $=6.9265 \mathrm{mg}(1)$, heating rate $=10 \mathrm{deg} / \mathrm{min}$, dynamic artificial air atmosphere, temperature range $25-900{ }^{\circ} \mathrm{C}$, aluminum oxide crucible.

\subsection{Single crystal X-ray diffraction}

Single-crystal X-ray data were collected on an Oxford Diffraction Xcalibur diffractometer equipped with a Sapphire3 CCD detector and a graphite monochromator utilizing Mo-K $\alpha$ radiation $(\lambda=0.71073 \AA$ ). Absorption corrections were based on the multi-scan technique using $A B S P A C K$ [22]. The structures were solved by the program SIR92 [23] and refined against $\mathrm{F}^{2}$ using full-matrix least squares methods with the program SHELXL-2014/7 [24]. Anisotropic displacement parameters were refined for all non-hydrogen atoms. The hydrogen atoms bonded to carbon atoms were included at idealized positions and refined as riders with isotropic displacement parameters assigned as 1.2 times the $U_{\text {eq }}$ values of their corresponding bonding partners, while the hydrogen atoms of the aqua ligands were located in a difference map and refined with restrained geometry and constrained isotropic thermal parameters $\left[U_{i s o}(\mathrm{H})\right.$ was $1.5 U_{e q}$ of the parent atom]. Some geometric parameters were calculated using the program PARST [25]. The crystal and experimental data are given in Table 1, and selected geometric 
parameters are given in Table 2. Possible hydrogen bonds are gathered in Table 3. The structural figures were drawn using Diamond [26].

Table 1. Crystal data and structure refinement for 1, 2 and $\mathbf{3 .}$

\begin{tabular}{|c|c|c|c|}
\hline & 1 & 2 & 3 \\
\hline CSD number & 1983891 & 1983890 & 1983889 \\
\hline Empirical formula & $\mathrm{C}_{18} \mathrm{H}_{20.31} \mathrm{O}_{5.17} \mathrm{~N}_{2} \mathrm{Ni}$ & $\mathrm{C}_{20} \mathrm{H}_{26} \mathrm{~N}_{2} \mathrm{NiO}_{6}$ & $\mathrm{C}_{21} \mathrm{H}_{28} \mathrm{~N}_{2} \mathrm{NiO}_{6}$ \\
\hline Molecular weight & 405.85 & 449.14 & 463.16 \\
\hline Crystal system & orthorhombic & triclinic & monoclinic \\
\hline Space group & Pbcn & P-1 & $\mathrm{P} 2{ }_{1} / \mathrm{n}$ \\
\hline \multicolumn{4}{|l|}{ Unit cell dimensions } \\
\hline$a(\AA)$ & $19.6607(6)$ & $7.8460(2)$ & $14.1325(7)$ \\
\hline$b(\AA)$ & $11.8032(4)$ & $11.4533(3)$ & $7.4085(4)$ \\
\hline$c(\AA)$ & $15.0266(4)$ & $12.2907(3)$ & $20.1164(8)$ \\
\hline$\alpha\left(^{\circ}\right)$ & 90 & $76.702(2)$ & 90 \\
\hline$\beta\left(\left(^{\circ}\right)\right.$ & 90 & $79.967(2)$ & $93.527(4)$ \\
\hline$\gamma\left({ }^{\circ}\right)$ & 90 & $70.233(2)$ & 90 \\
\hline$V\left(\AA^{3}\right)$ & $3487.05(18)$ & $1005.90(5)$ & $2102.21(18)$ \\
\hline$Z$ & 8 & 2 & 4 \\
\hline$D_{\text {calc }}\left(\mathrm{Mg}_{\mathrm{m}} \mathrm{m}^{-3}\right)$ & 1.546 & 1.483 & 1.463 \\
\hline $\mathrm{T}(\mathrm{K})$ & $100(2)$ & $100(2)$ & $173(2)$ \\
\hline$\mu\left(\mathrm{mm}^{-1}\right)$ & 1.146 & 1.004 & 0.963 \\
\hline Crystal dimensions (mm) & $0.217 \times 0.240 \times 0.503$ & $0.121 \times 0.232 \times 0.355$ & $0.017 \times 0.033 \times 0.379$ \\
\hline Crystal color / form & red block & red block & brown needle \\
\hline \multirow[t]{3}{*}{ Index ranges } & $-22 \leq h \leq 24$ & $-9 \leq h \leq 9$ & $-17 \leq h \leq 17$ \\
\hline & $-13 \leq k \leq 14$ & $-14 \leq k \leq 14$ & $-8 \leq k \leq 9$ \\
\hline & $-18 \leq l \leq 18$ & $-15 \leq l \leq 15$ & $-24 \leq l \leq 24$ \\
\hline$\theta$ range $\left(^{\circ}\right)$ & $2.902-25.998$ & $3.411-26.498$ & $3.240-25.998$ \\
\hline Reflections collected & 27510 & 35818 & 14980 \\
\hline $\mathrm{R}_{\text {int }}$ & 0.0489 & 0.0164 & 0.0718 \\
\hline Independent reflections & 3433 & 4154 & 4130 \\
\hline Observed reflections $[I>2 \sigma(I)]$ & 3004 & 3867 & 2988 \\
\hline$T_{\min }-T_{\max }$ & $0.602-1.000$ & $0.818-1.000$ & $0.885-1.000$ \\
\hline Goodness-of-fit on $F^{2}$ & 1.036 & 1.038 & 1.010 \\
\hline \multirow[t]{2}{*}{$R$ indices $[I>2 \sigma(I)]$} & $R_{1}=0.0331$ & $R_{1}=0.0242$ & $R_{1}=0.0436$ \\
\hline & $w R_{2}=0.0840$ & $w R_{2}=0.0609$ & $w R_{2}=0.0826$ \\
\hline \multirow[t]{2}{*}{$R$ indices (all data) } & $R_{1}=0.0394$ & $R_{1}=0.0267$ & $R_{1}=0.0739$ \\
\hline & $w R_{2}=0.0887$ & $w R_{2}=0.0625$ & $w R_{2}=0.0922$ \\
\hline Diff. peak and hole $\left(\mathrm{e} . \AA^{-3}\right)$ & $0.374 ;-0.287$ & $0.339 ;-0.225$ & $0.868^{*} ;-0.323$ \\
\hline
\end{tabular}

* this maximum was located near $(0.998 \AA$ ) the $\mathrm{Ni}(\mathrm{II})$ central atom; the next maximum exhibits a value of 0.33 e. $\AA^{-3}$

2.6. Energy decomposition calculations

A simple energy decomposition scheme has been used to analyze components of interaction energy between $\mathrm{Ni}$ (II) complexes in the dimeric systems $\mathbf{2}$ and $\mathbf{3}$ at B3LYP-D3/TZVP level. All calculations were performed with ORCA 4.2.1 computational package using the experimental geometry of the complexes under study [27]. The energy decomposition method has been used as implemented in the Multiwfn v3.3.8 program suite [28].

\section{Results and Discussion}




\subsection{Preparation and identification}

The direct reaction of the Schiff base $\mathrm{H}_{2}$ (o-van-en) with nickel(II) carbonate under reflux leads to a microcrystalline product of $\mathbf{1}[\mathrm{Ni}(o-v a n-e n)] \cdot n \mathrm{H}_{2} \mathrm{O}(n=1.17 ; \mathbf{1})$. Diffraction data for $\mathbf{1}$ were measured at $\mathrm{T}=100 \mathrm{~K}(\mathrm{LT})$ and at $\mathrm{T}=293 \mathrm{~K}(\mathrm{RT})$. We report here the results derived from the LT data set. A summary of crystal data and refinement results for $\mathbf{1}$ at RT is given in Table $\mathrm{S} 1$; the RT results have also been deposited in the CSD. The identity and purity of 1 were corroborated by powder X-ray diffraction (Fig. 1), using the RT single-crystal analysis as a point of departure for the Le Bail refinement. Complex $\mathbf{1}$ is easily soluble in different organic solvents. We recrystallized this product form acetone, ethanol and isopropanol. Single crystals of various solvatomorphs were obtained in the form of the hydrate (recrystallization from acetone) $\mathbf{1}$, the monohydrate-monoethanol solvate (from ethanol) $\mathbf{2}$, and the monohydratemonoisopropanol solvate (recrystallization from isopropanol) 3. While crystals of $\mathbf{1}$ present more regular proportions, crystals of $\mathbf{3}$ are small, thin needles; compound $\mathbf{2}$ crystallized with a shape intermediate between those of 1 and 3 (Fig. S1 in the Electronic Supplementary Information). A literature survey has shown that the hydrate $\mathbf{1}$ in the form of the monohydrate $(n=1)$ prepared by crystallization from chloroform was already structurally elucidated based on room temperature data with a higher final residual value of $R=7.1 \%$ [17]. Additional systems comprising [Ni(o-van-en $)]$ complex molecules are also recorded in the CSD [29]: the chloroform solvate, $[\mathrm{Ni}(o$-van-en $)] \cdot \mathrm{CHCl}_{3}$ (Ref-code TEJGIZ) which was prepared by the solid state reaction of the Schiff base $\mathrm{H}_{2}$ (o-van-en) with nickel(II) acetate tetrahydrate followed by recrystallization from chloroform [15], and the dimethylformamide solvate, [Ni(o-vanen)] $\cdot \mathrm{Me}_{2} \mathrm{~N}-\mathrm{CHO}$ (ULAMIE) prepared by recrystallization from dimethylformamide [16]. In addition, several co-crystals of [ $\mathrm{Ni}(o-v a n-e n)]$ with various tin complexes were reported, e.g., $[\mathrm{Ni}(o$-van-en $)] \cdot\left(\mathrm{H}_{2} \mathrm{O}\right) \cdot \mathrm{SnMe}_{2} \mathrm{Cl}_{2}$ (WAVYOH) [17]. We note also the existence of a report on the synthesis and crystal structure of $\left[\mathrm{Ni}(o-v a n-e n)\left(\mathrm{H}_{2} \mathrm{O}\right)\right]$ (YUDFIN) with a pentacoordinated $\mathrm{Ni}(\mathrm{II})$ atom [30]. 


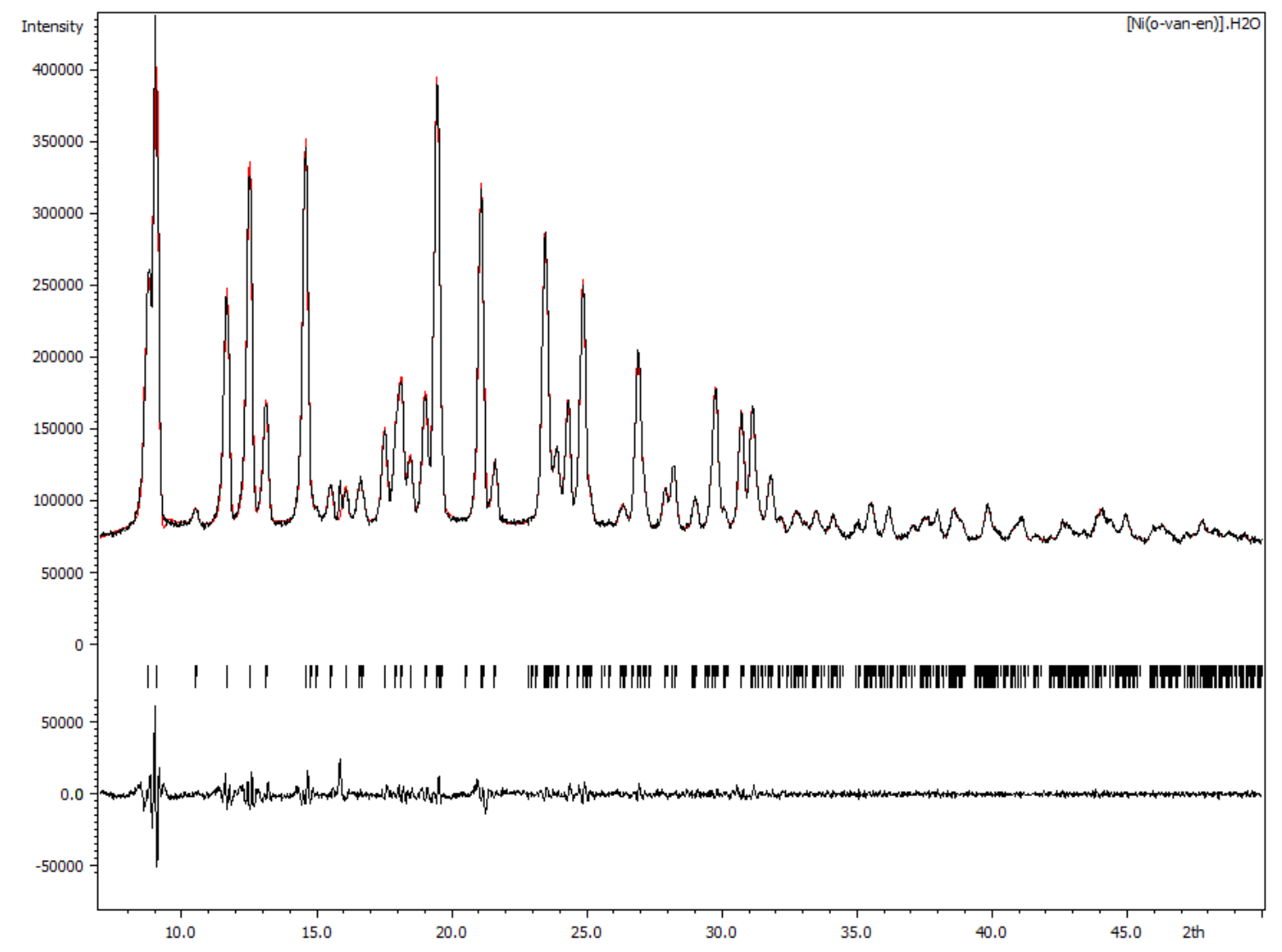

Figure 1 Results of Le Bail refinement of the powder diffraction pattern of $\mathbf{1}$, with the unit-cell parameters taken from the known crystal structure of $[\mathrm{Ni}(o$-van-en $)] \cdot n \mathrm{H}_{2} \mathrm{O}(n=1.16$, see Table 1). The refined cell parameters are $a=19.6242$ (3) $\AA, b=11.873$ (2) $\AA, c=15.224$ (2) $\AA$. $R(p)$ $=0.0172, R(w p)=0.0258$, goodness of fit $=8.34$.

All three solvatomorphs 1-3 display content-rich IR spectra. The positions of the main absorption bands are gathered in the experimental section and the respective spectra are depicted in Fig. 2 (complex 1), Fig. S2 (Schiff-base), Fig. S3 (2) and Fig. S4 (3) (Figures S2S4 are in the Supplementary File). Characteristic signals include pairs of strong absorption bands positioned at 1621 and $1602 \mathrm{~cm}^{-1}$ in 1,1621 and $1602 \mathrm{~cm}^{-1}$ in 2 , and 1622 and 1603 $\mathrm{cm}^{-1}$ in 3 , respectively, which, according to the literature, can be assigned to $v(\mathrm{C}=\mathrm{N})$ vibrations $[31,32]$. In the IR spectrum of the uncoordinated Schiff base $\mathrm{H}_{2}$ (o-van-en) this band appeared at $1631 \mathrm{~cm}^{-1}$ and this value is very close to that of $1633 \mathrm{~cm}^{-1}$ reported previously [31]. Weak to very weak but easily identifiable are the absorption bands positioned slightly above $3000 \mathrm{~cm}^{-1}$ [3055 $\mathrm{cm}^{-1}$ (1), $3055 \mathrm{~cm}^{-1}$ (2) and $\left.3056 \mathrm{~cm}^{-1}(\mathbf{3})\right]$ due to $v\left(\mathrm{C}_{\mathrm{ar}}-\mathrm{H}\right)$ stretching vibrations; the corresponding band in the Schiff base was observed at $3087 \mathrm{~cm}^{-1}$. Medium-broad absorption bands observed around $3500 \mathrm{~cm}^{-1}\left(3454 \mathrm{~cm}^{-1}\right.$ in $\mathbf{1}, 3446 \mathrm{~cm}^{-1}$ in 2 and $3330 \mathrm{~cm}^{-1}$ in 3$)$ were, in accord with the literature [33], assigned to $v(\mathrm{O}-\mathrm{H})$ vibrations; we note the presence of two 
sharper absorption bands positioned at 3508 and $3478 \mathrm{~cm}^{-1}$ in the IR spectrum of $\mathbf{3}$ which can be assigned to the $v(\mathrm{O}-\mathrm{H})$ vibrations from the isopropanol solvate molecule.

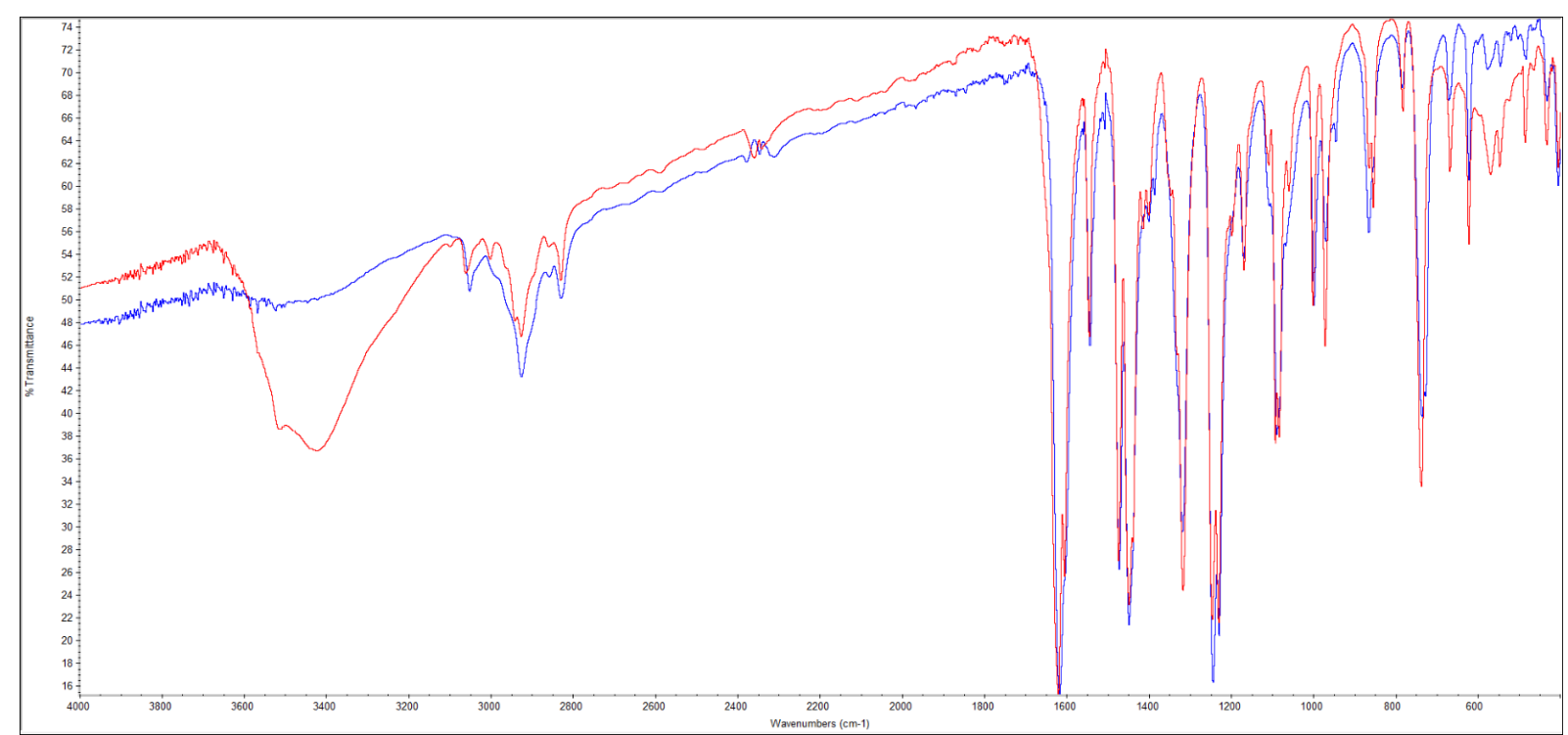

Figure 2 IR spectrum of 1 at RT (red) and at $140{ }^{\circ} \mathrm{C}$ (blue).

Thermodynamic data were measured for the hydrate solvatomorph 1 with the aim of elucidating its thermal stability and to corroborate the presence of water solvate molecules (Fig. 3). As can be seen from Fig. 3 complex 1 begins to lose weight smoothly, already at room temperature and this process is endothermic with DTA $\mathrm{Dax}_{\max }$ at $95{ }^{\circ} \mathrm{C}$. The experimental weight loss $(5.0 \%)$ corresponds well to the calculated value for full dehydration $(5.1 \%$ calculated for $n=1.16$ ). Upon further heating a plateau on the TG curve was observed which indicates formation of the anhydrous complex [Ni(o-van-en)], stable within the temperature range 100$200{ }^{\circ} \mathrm{C}$. The IR spectrum of 1 measured at $140^{\circ} \mathrm{C}$ (blue line in Fig. 3, Fig. S5) does not contain absorption bands of the $v(\mathrm{OH})$ and $\delta\left(\mathrm{H}_{2} \mathrm{O}\right)$ types (weak shoulder at $1670 \mathrm{~cm}^{-1}$ ) corroborating the full dehydration of $\mathbf{1}$. Further heating in the temperature range of 320-420 ${ }^{\circ} \mathrm{C}$ causes the total decomposition of the dehydrated sample. The solid residue represents $17.0 \%$ of the initial weight; the calculated values for $\mathrm{NiO}$ and metallic nickel are 18.4 and $14.5 \%$, respectively. 


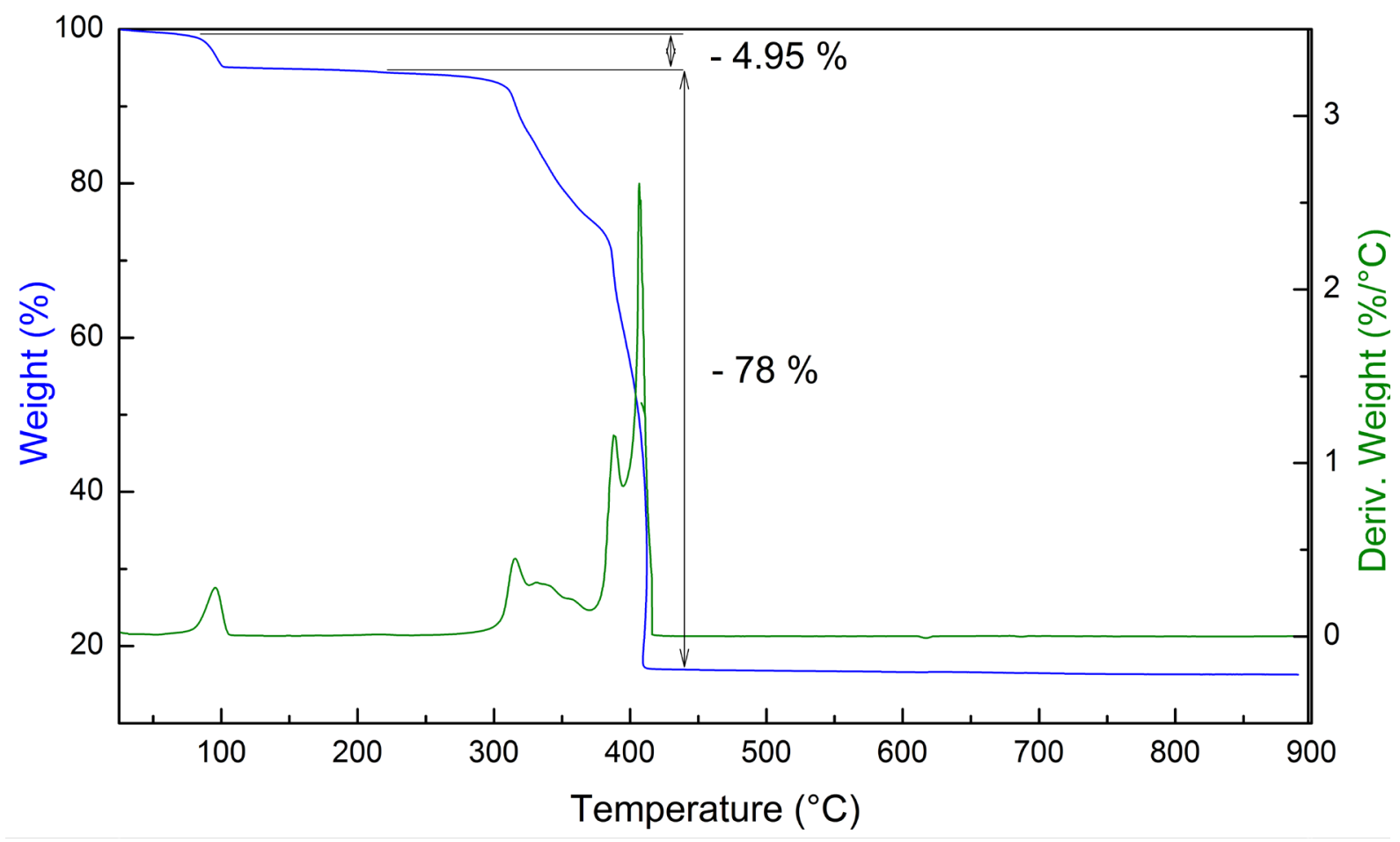

Figure 3. Thermal curves for 1.

\subsection{Crystal structures}

The Schiff base type ligand (o-van-en) ${ }^{2-}$ exhibits two compartments, a smaller one with cis$\mathrm{N}_{2} \mathrm{O}_{2}$ donor set and a larger one with $\mathrm{O}_{4}$ donor set; the $\mathrm{O}$ atoms formed by deprotonation of the hydroxido groups are common donor atoms for both compartments, usually forming $\mathrm{O}$ monoatomic bridges between the M1 and M2 central atoms placed in the smaller and larger cavities, resp.

Because of its stereochemical properties and its ability to act as a chaperone for two entities that would not otherwise come into proximity, this ligand is often used for syntheses of new complexes. A search in the CSD [29] yielded 349 hits for complexes formed by (o-van$e n)^{2-}$ with any metallic element M1 present in the smaller compartment. As expected, the most numerous complexes are those with $\mathrm{M} 1=\mathrm{Cu}$ (II) with 106 hits in CSD, among these 72 hits for tetracoordinated (square) and 32 hits for pentacoordinated (square pyramidal) $\mathrm{Cu}(\mathrm{II})$ and 2 hits for hexacoordinated $\mathrm{Cu}(\mathrm{II})$. It seems the smaller compartment, due to its size, contributes to the stability of manganese(III); there are 68 hits for such complexes and only 2 hits for Mn(II) complexes. Also numerous complexes with M1 = Ni(II) in square coordination (54 hits) and those with $\mathrm{Zn}$ (II) being almost exclusively pentacoordinated (53 hits, only 1 structure contains a hexacoordinated $\mathrm{Zn}(\mathrm{II})$ center). Among the other $3 d$ metals maybe surprisingly we find only eight crystal structures with $\mathrm{M} 1=\mathrm{Co}(\mathrm{III})$ and an additional two with $\mathrm{Co}(\mathrm{II})$. Much less numerous are complexes with vanadium(IV, V), with 12 hits (coordination numbers 5 or 6), iron (10 hits); and for the $3 d$ metals titanium(IV) and chromium(III) there were two and one entries, respectively. 
Surprisingly, there are additional crystal structures reported with larger central M1 atoms, vis.: Cd (1 hit), Ru (6 hits), U (3), Pt (5, square), Pd(II) (2, square), Tb(III) (1 hit), Dy(III) (1), Ho(III) (1), Bi(III) (1), Th(IV) (1). It is interesting that in the case of Dy(III) complex PIDXIM and Ho(III) complex PIDXOS a sandwich-like arrangement of two (o-van-en $)^{2-}$ ligands around the $\mathrm{Ln}(\mathrm{III})$ atom is formed [34 ].

As mentioned above, there are 55 hits in CSD for compounds containing the structural unit $\{\mathrm{Ni}($ o-van-en $)\}$; in 54 cases the $\mathrm{Ni}(\mathrm{II})$ atom is in square coordination while in one hit (YUDFIN) unusual pentacoordinated $\mathrm{Ni}(\mathrm{II})$ atom is reported [30]. In all these complexes the smaller compartment is occupied by a square coordinated $\mathrm{Ni}$ (II) atom while the larger compartment is available for further use (Table S2). Three different uses (functionalization of the $\mathrm{O}_{4}$ donor set) for the larger compartment exist, as recorded in the CSD:

1. The second compartment is occupied by an another metallic atom, usually with a larger ionic radius ( $4 d-, 5 d-, p$ - or $4 f$-metal) with one exception for the $3 d$-metal Mn(II). In this case all donor atoms $\mathrm{O}_{4}$ form coordination bonds to the metallic element which completes its coordination sphere with additional co-ligands. If these co-ligands are terminal or chelating, dinuclear complexes are formed. If at least one co-ligand exhibits bridging character, trinuclear (some hexacyanidocomplexes) or even complexes with higher nuclearities can be formed with 10 being the highest. Sometimes dimerization of the dinuclear unit enhances the nuclearity.

2. The second compartment is occupied by an alkali metal or alkali-earth cation. In this case various structures were reported. In some cases the metal atom enters the larger cavity and is placed within the plane of metalloligand $\{\mathrm{Ni}(o-v a n-e n)\}$, while in other cases the metal is placed inside the space between a pair of $\{\mathrm{Ni}(o$-van-en $)\}$ structural units and this arrangement often leads to a chain-like arrangement of parallel-stacked $\{\mathrm{Ni}(o-v a n-e n)\}$ structural units with $\mathrm{M}$ placed between them.

3. The second compartment lacks any metal atom. In this case the structural unit $\{\mathrm{Ni}(o-$ van-en)\} can be viewed as the host part of a host-guest compound and is used for accommodation of an additional guest molecule, like water (also as aqua ligand), ethanol, ammonium cation, etc. Usually, the guest molecule is not situated in the plane of the $\{\mathrm{Ni}(o-v a n-e n)\}$ as they are pushed outside the plane by formation of hydrogen bonding interactions with the inner $\mathrm{O}$ atoms. If only solvent molecules are present in the structure, formation of solvatomorphs is observed. On the other hand, the presence of additional molecules (not solvent) results in the formation of co-crystals.

In conclusion, for the $\{\mathrm{Ni}(o-v a n-e n)\}$ structural unit (in the solid state) a high tendency to use/functionalize the four inner oxygen atoms is typical, presumably in order to enhance the lattice energy $U_{\mathrm{g}}$ and this contributes to the stability of the crystal structure with at least a solvent molecule.

\subsubsection{Molecular structure of the complex molecule}


All three solvatomorphs 1, 2 and $\mathbf{3}$ contain the same complex molecule [Ni(o-van-en $)]$ with the $\mathrm{Ni}(\mathrm{II})$ central atom residing within the square $\mathrm{O}_{2} \mathrm{~N}_{2}$ donor set of the $(o \text {-van-en })^{2-}$ anion $\left(\mathrm{NiN}_{2} \mathrm{O}_{2}\right.$ chromophore) formed by two nitrogen atoms from the ethane-1,2-diamine fragment and two phenoxido oxygen atoms (Figs. 4-6). The room temperature crystal structure of $\mathbf{1}$, characterized as [Ni(o-van-en $)] \cdot n \mathrm{H}_{2} \mathrm{O}$ with $n=1$, has been reported twice; in both cases, WAVZAU [17] and WAVZAU01 [35], the final $R_{1}$ were 0.071 . We have collected low temperature data which yielded a better final $R_{1}=0.0333$ (Table 1), and, in addition, the results of structure refinement suggests the presence of an additional, partially occupied site for a water solvate molecule resulting in $n=1.16$ (see below). The lower temperature of our data collection $(100 \mathrm{~K})$ manifests itself in a smaller unit cell volume of $3487.05(18) \AA^{3}$ as compared to the value of $3574.26 \AA^{3}$ (RT) reported for WAVZAU [17].

The same complex molecule [Ni(o-van-en)] is also present in two further solvatomorphs with chloroform $[\mathrm{Ni}($ o-van-en $)] \cdot \mathrm{CHCl}_{3}$ (TEJGIZ, 4) [15] and dimethylformamide $\left(\mathrm{C}_{3} \mathrm{H}_{7} \mathrm{NO}\right.$, DMFA) [Ni(o-van-en)].DMFA (ULAMIE, 5) [16]. It should be noted that all solvatomorphs 15 crystallize in centrosymmetric space groups so both possible conformations of the ethane1,2-diamine fragment in (o-van-en $)^{2-}$ are present in the unit cell in equimolar ratio.

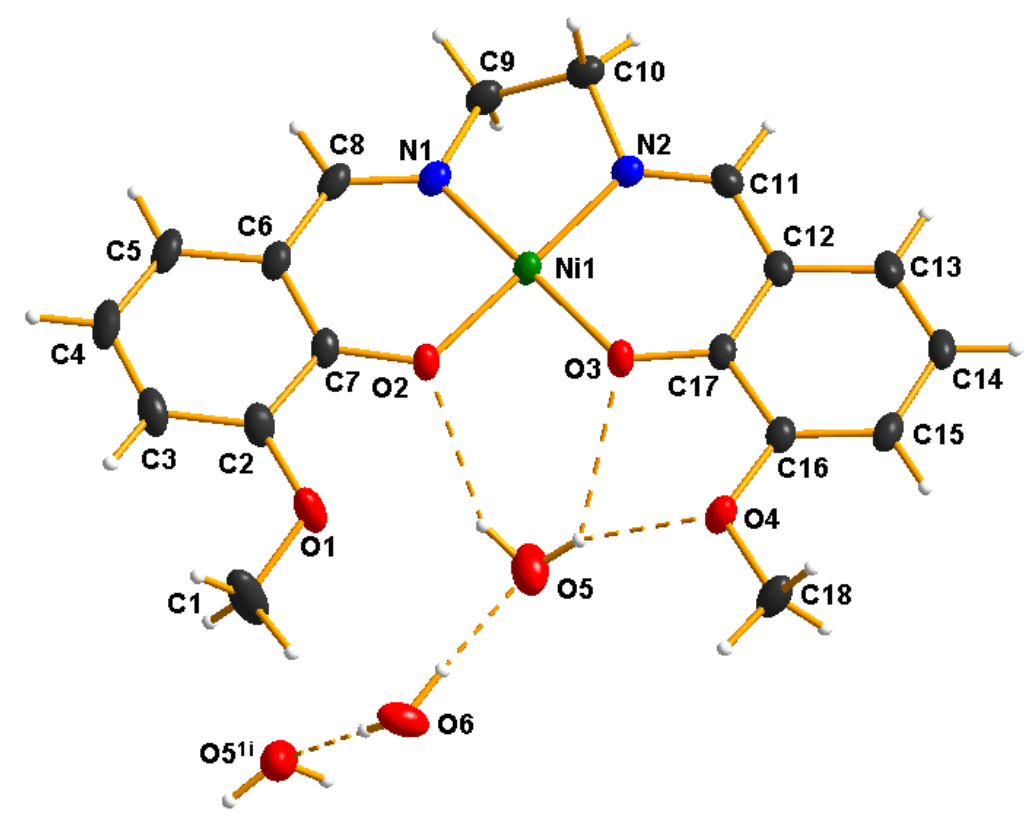

Figure 4 Molecular structure of 1 showing the atom labeling scheme. The thermal ellipsoids are drawn at $30 \%$ probability level. The position for O6 water molecule is partially occupied.

Dashed lines represent possible hydrogen bonds. Symmetry code: 1i: 1-x, y, 0.5-z 


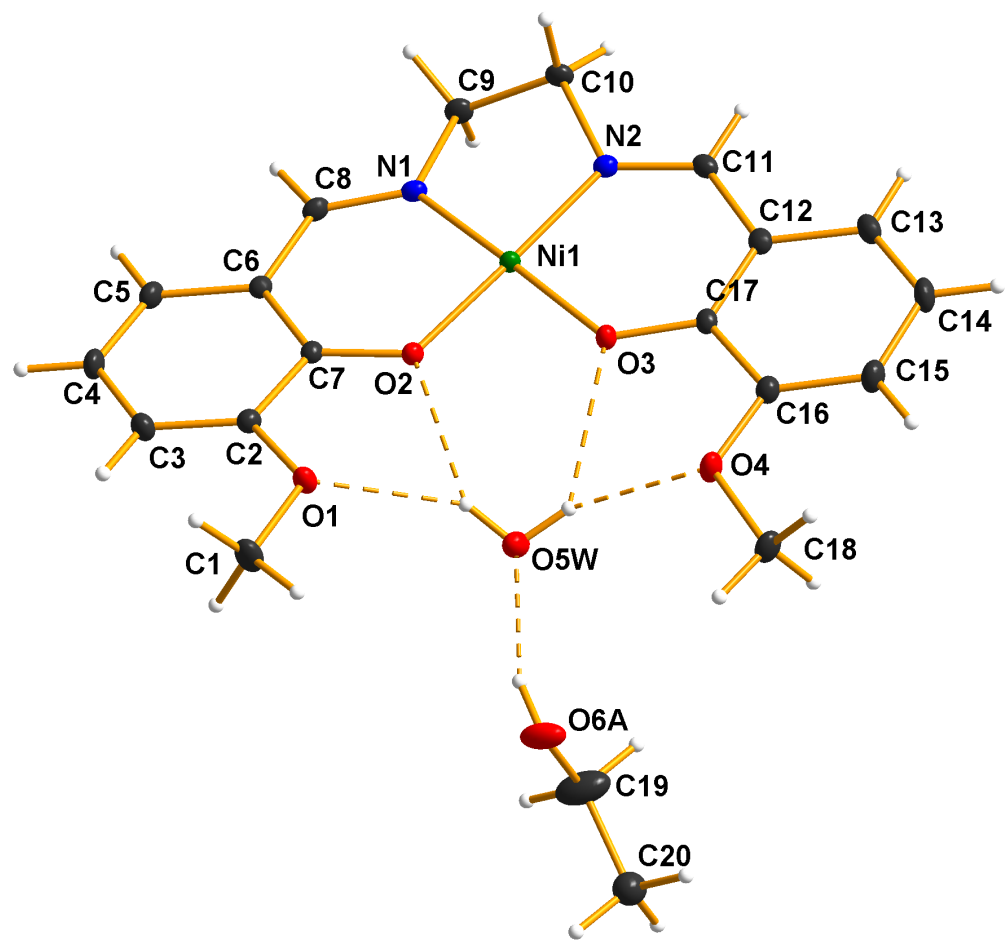

Figure 5 Molecular structure of $\mathbf{2}$ showing the atom labeling scheme. The thermal ellipsoids are drawn at $30 \%$ probability level. Only the more populated position (s.o.f. $=0.60(2)$ ), of O6 atom as well as the corresponding hydrogen atoms of the ethanol solvate molecule, are depicted. Dashed lines represent possible hydrogen bonds. 


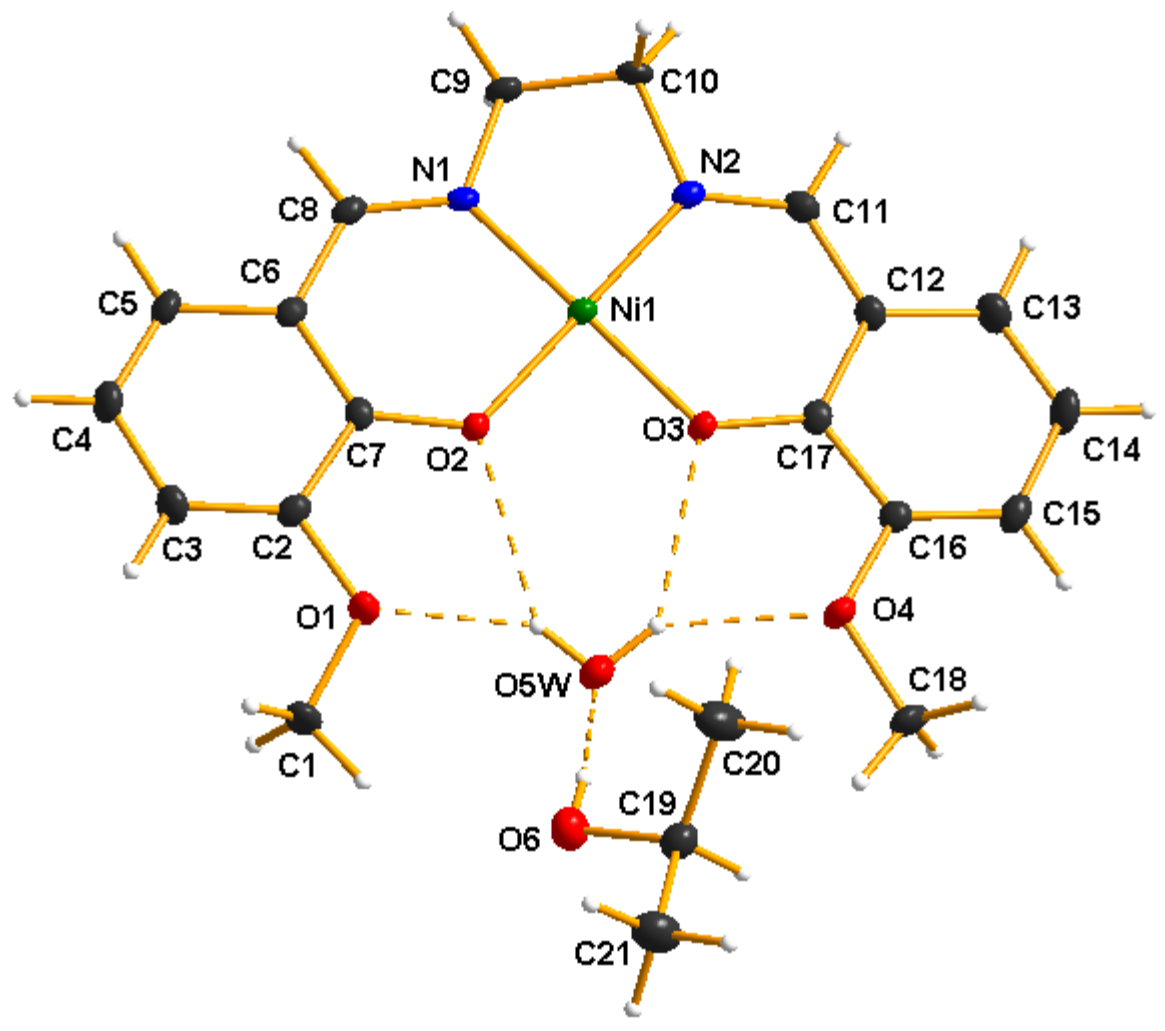

Figure 6 Molecular structure of $\mathbf{3}$ showing the atom labeling scheme. The thermal ellipsoids are drawn at $30 \%$ probability level. Dashed lines represent possible hydrogen bonds.

Selected geometric parameters of the solvatomorphs 1-3 along with those reported for the known compounds $\mathbf{4}$ and $\mathbf{5}$ are gathered in Table 2. As can be seen from this table the $\mathrm{Ni}-\mathrm{N}$ and Ni-O bond distances fall within the narrow ranges 1.843(2) (in 4) - 1.8552(12) $\AA$ (in 2) and 1.8392(17) (in TEJGIZ) - 1.8651(18) $\AA$ (in 3), respectively, in line with the rigidity of the square coordination. In nickel(II) complexes with the analogous tetradentate Schiff base obtained by condensation of 1,3-propanediamine with 2-hydroxybenzophenone in a 1:2 molar ratio, the corresponding $\mathrm{Ni}-\mathrm{N}$ and $\mathrm{Ni}-\mathrm{O}$ bond distances are in the ranges $1.877(2)-1.883(2) \AA$ and 1.824(2) - 1.852(2) $\AA$, respectively, demonstrating somewhat longer Ni-N distances [32] presumably as a consequence of the larger metallocycle formed by 1,3-diamine fragment with respect to the 1,2-diamine in our case. The small variation of coordination bond distances also manifests itself in near uniformity of the values of the cis- N-Ni-N and O-Ni-O angles in 1-5; these lie in the range 84.18(7) (O-Ni-O angle in 4) - 86.60(9) ( N-Ni-N angle in 4). The corresponding geometric parameters in the RT hydrate $(\mathbf{1}, n=1)$ are very close to these ranges [17].

Table 2 Comparison of selected geometric parameters $\left[\AA,^{\circ}\right]$. 


\begin{tabular}{|c|c|c|c|c|c|}
\hline & $\begin{array}{l}1 \\
(n=1.16) \\
\text { This work } \\
\mathrm{T}=100 \mathrm{~K}\end{array}$ & $\begin{array}{l}2 \\
\text { This work } \\
\mathrm{T}=100 \mathrm{~K}\end{array}$ & $\begin{array}{l}3 \\
\text { This work } \\
\mathrm{T}=173 \mathrm{~K}\end{array}$ & $\begin{array}{l}4 \text { TEJGIZ } \\
{[15]} \\
\mathrm{T}=296 \mathrm{~K}\end{array}$ & $\begin{array}{l}5 \text { ULAMIE } \\
{[16]} \\
T=110 \mathrm{~K}\end{array}$ \\
\hline $\mathrm{Ni}-\mathrm{N}$ & $\begin{array}{l}1.8509(16) \\
1.8547(18)\end{array}$ & $\begin{array}{l}1.8461(12) \\
1.8552(12) \\
\end{array}$ & $\begin{array}{l}1.849(2) \\
1.852(2)\end{array}$ & $\begin{array}{l}1.846(2) \\
1.843(2)\end{array}$ & $\begin{array}{l}1.8502(17) \\
1.8503(17) \\
\end{array}$ \\
\hline $\mathrm{Ni}-\mathrm{O}$ & $\begin{array}{l}1.8469(13) \\
1.8607(14)\end{array}$ & $\begin{array}{l}1.8577(10) \\
1.8599(10)\end{array}$ & $\begin{array}{l}1.8650(18) \\
1.8651(18)\end{array}$ & $\begin{array}{l}1.8392(17) \\
1.8458(17)\end{array}$ & $\begin{array}{l}1.8609(13) \\
1.8594(13)\end{array}$ \\
\hline cis $(\mathrm{N}-\mathrm{Ni}-\mathrm{N})$ & $85.67(7)$ & $86.03(5)$ & $85.78(10)$ & $86.60(9)$ & $85.71(8)$ \\
\hline cis $(\mathrm{O}-\mathrm{Ni}-\mathrm{O})$ & $85.68(6)$ & $85.17(4)$ & $85.96(8)$ & $84.18(7)$ & $85.14(6)$ \\
\hline $\begin{array}{l}\mathrm{C} 1-\mathrm{O} 1-\mathrm{C} 2-\mathrm{C} 3 \\
\mathrm{C} 18-\mathrm{O} 4-\mathrm{C} 16-\mathrm{C} 15\end{array}$ & $\begin{array}{l}10.9(3) \\
5.9(3)\end{array}$ & $\begin{array}{l}2.1(2) \\
-9.2(2)\end{array}$ & $\begin{array}{l}12.9(4) \\
-6.3(4)\end{array}$ & $\begin{array}{l}-6.93 \\
16.17\end{array}$ & $\begin{array}{l}-6.90 \\
3.20\end{array}$ \\
\hline $\begin{array}{l}\text { Angle between the } \\
\text { aromatic rings }\end{array}$ & $3.76(5)$ & $7.54(5)$ & $4.27(8)$ & 3.41 & 3.87 \\
\hline $\begin{array}{l}\text { Angles between the } \\
\text { aromatic rings and } \\
\text { eq. plane }\left\{\mathrm{N}_{2} \mathrm{NiO}_{2}\right\}\end{array}$ & $\begin{array}{l}5.78(4) \\
9.50(5) \\
\end{array}$ & $\begin{array}{l}7.28(4) \\
1.03(4)\end{array}$ & $\begin{array}{l}3.72(8) \\
5.73(8) \\
\end{array}$ & $\begin{array}{l}5.38 \\
8.47 \\
\end{array}$ & $\begin{array}{l}7.65 \\
6.89 \\
\end{array}$ \\
\hline $\begin{array}{l}\text { Shortest } \mathrm{Ni} \cdots \mathrm{Ni} \\
\text { distance and } \\
\text { type of supramo- } \\
\text { lecular structure }\end{array}$ & $\begin{array}{l}6.2080(4) \\
0.5-x, 0.5+y, z \\
\text { monomer }\end{array}$ & $\begin{array}{l}3.3379(3) \\
1-x, 1-y, 1-z \\
\text { dimer }\end{array}$ & $\begin{array}{l}3.3712(6) \\
1-x, 1-y, 1-z \\
\text { dimer }\end{array}$ & (dimer) & (chain) \\
\hline
\end{tabular}

The complex molecules $[\mathrm{Ni}(o-v a n-e n)]$ in the respective solvatomorphs deviate somewhat from planarity, presumably due to the action of packing forces (Figs. S6-S8). The deviation from planarity can be demonstrated by the non-co-planarity of the two aromatic rings (atoms $\mathrm{C} 2-\mathrm{C} 7$ and atoms $\mathrm{C} 12-\mathrm{C} 17$ ) of the vanillin fragments as well as by the non-zero angles between the aromatic rings of the vanillin fragments and the equatorial mean plane formed by the $\left\{\mathrm{NiN}_{2} \mathrm{O}_{2}\right\}$ atoms. The range for the dihedral angle between the aromatic rings is 3.41 - $7.54(5)^{\circ}$ with the greatest value for 2 (water and ethanol solvate molecules); and the range for the second angle is $1.03(4)-9.50(5)^{\circ}$ with the largest value found in 1 . Different packing forces manifest themselves also in the variation of the positions of the methoxy groups which are sometimes significantly pushed out from the plane of the complex molecule with the highest values of $12.9(4)^{\circ}$ and $16.17^{\circ}$ observed in 3 and $\mathbf{4}$, respectively, as indicated by the values of the corresponding C-O-C-C torsion angles (Table 2). The asymmetry in the positions of the two methoxy groups within the same complex molecule is also noteworthy. 
The small but significant conformational differences among the complex molecules [Ni(o-van-en)] in the respective solvatomorphs $\mathbf{1}, \mathbf{2}$ and $\mathbf{3}$, can be observed on a pairwise basis in Figure 7; comparisons of the solvatomorph $\mathbf{1}$ with those of $\mathbf{4}$ and $\mathbf{5}$ are depicted on Fig. S9a and Fig. S9b. A comparison of the molecular structure of 1 at $100 \mathrm{~K}(n=1.16)$ with the RT structure ( $n=1$; [17] (Fig. S9c) indicates only minor conformational differences which can be ascribed to temperature differences.

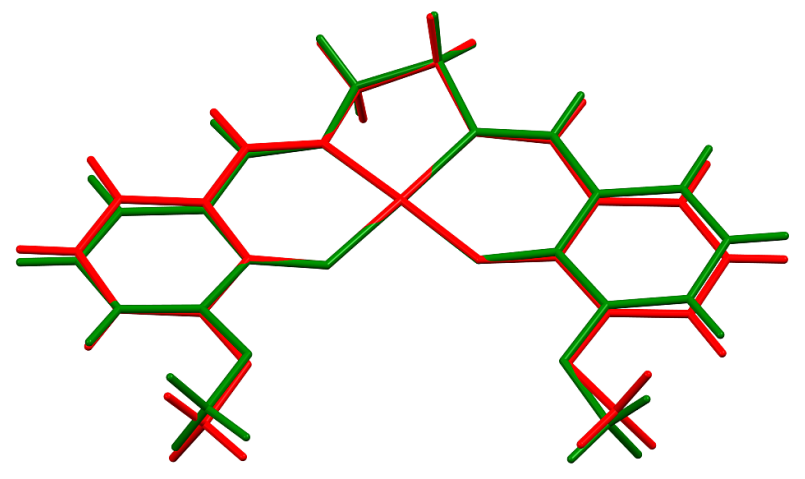

(a)

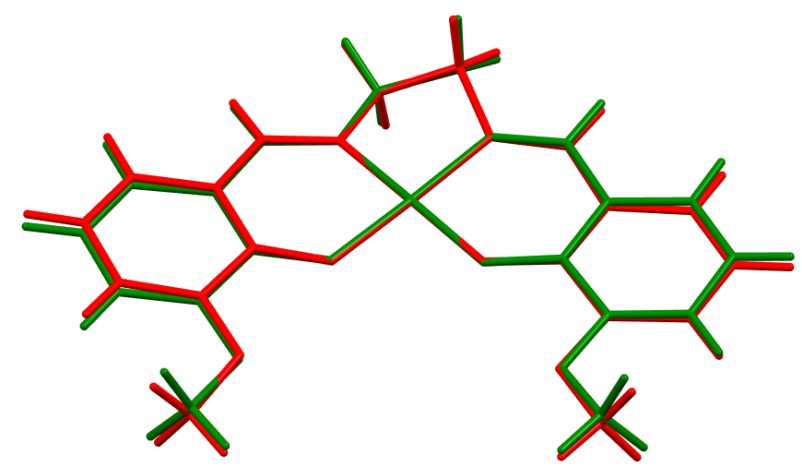

(b)

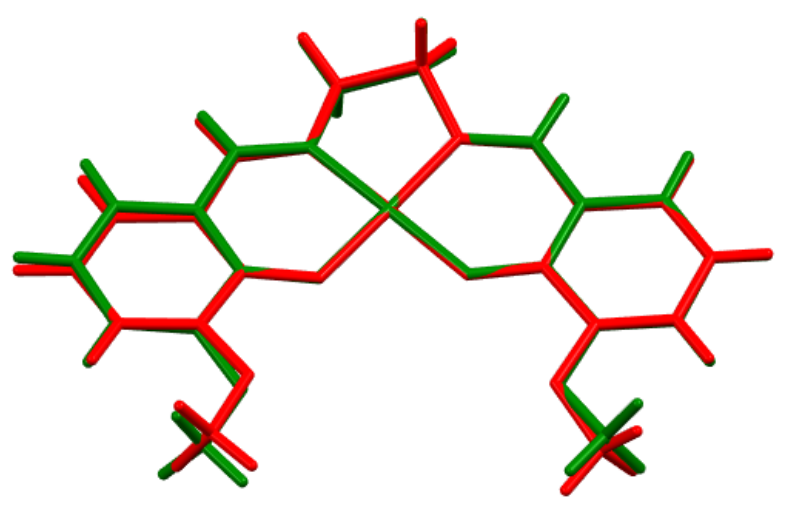

(c)

Figure 7. Comparison of the molecular structures of the complex molecules [Ni(o-van-en $)]$ in the pairs of solvatomorphs: a) $\mathbf{1}$ (red) and $\mathbf{2}$ (green); b) $\mathbf{1}$ (red) and $\mathbf{2}$ (green); c) $\mathbf{1}$ (red) and $\mathbf{2}$ (green). The structures are superimposed in such a way that the positions of the atoms in the $\left\{\mathrm{NiN}_{2} \mathrm{O}_{2}\right\}$ fragment are overlapped as closely as possible.

\subsubsection{Intramolecular interactions between the complex molecules and solvate molecules}

As a result of its shape the $[\mathrm{Ni}($ o-van-en $)]$ complex molecule possesses a compartment located between the two oxygen atoms from deprotonated hydroxyl groups and two methoxy groups. 
This compartment, as mentioned above, can serve for accommodation of an additional metal atom such as a lanthanide [11,36] or alkali metal [37,38]. In the absence of such a metal atom the resulting space is (possibly partially) occupied by a hydrogen-bonded solvate molecule, sometimes slightly displaced from the plane of the complex. In the structures of 1-3 the closest solvate molecule is water (Table 3), and its presence is complemented by an additional partially occupied water molecule (O6) in $\mathbf{1}$, and by ethanol and isopropanol molecules in $\mathbf{2}$ and $\mathbf{3}$, respectively.

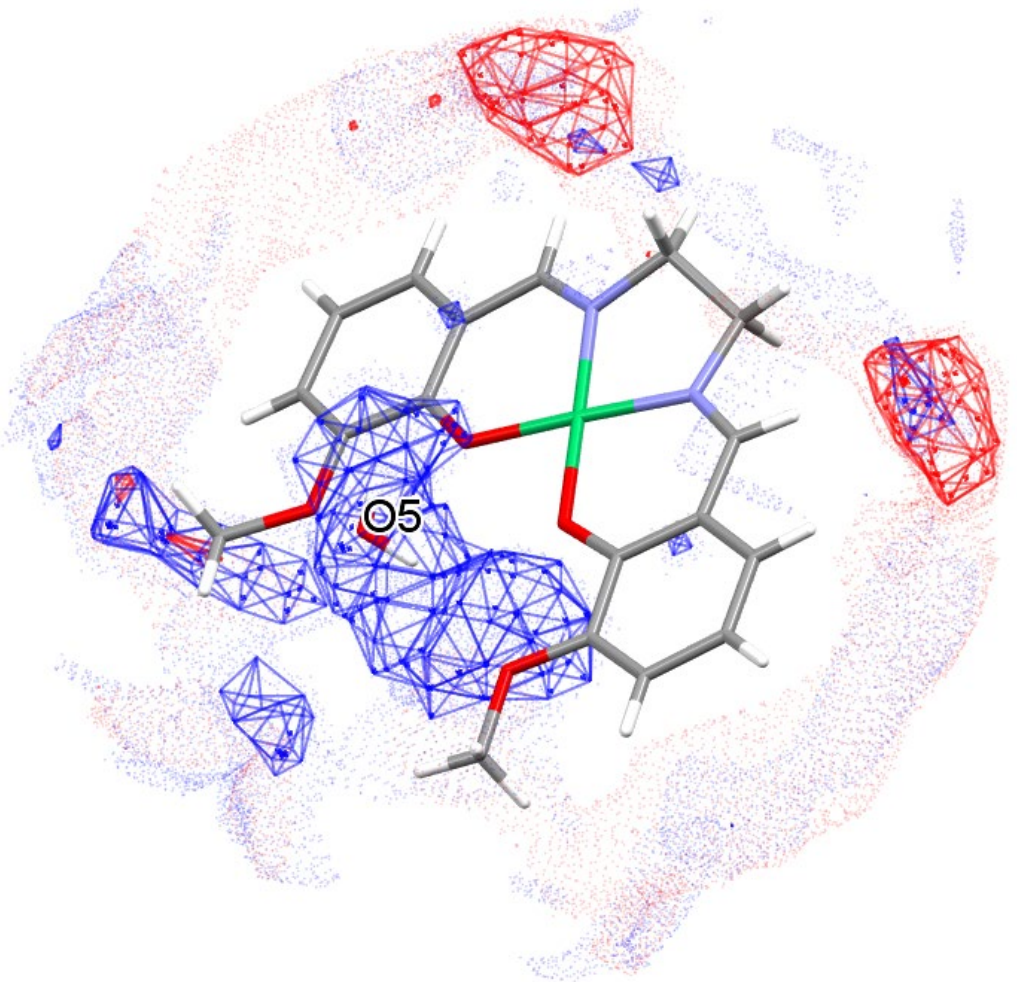

Figure 8 FIM showing the acceptor (oxygen atoms, red) and donor (water oxygens, blue) regions around the $[\mathrm{Ni}(o-v a n-e n)]$ complex molecule in $\mathbf{1}$. Dots, wireframe and nods represent frequencies of _2, 4 and 6 times those expected for a random distribution of contacts. The position of the $\mathrm{O} 5$ water solvate molecule is shown.

The calculated Full Interaction Map (FIM) [39] for 1 considering only the [Ni(o-vanen)] complex molecule indicates a blue donor region located in or nearby the larger compartment of the complex molecule. The O5 water solvate molecule is located within this region (Figure 8). The same observation pertains to the positions of the water solvate molecules in $\mathbf{2}$ and 3; the corresponding figures are in the Supplementary File (Fig. S10). In line with this the $\mathrm{O} 5$ water solvate molecules within the respective solvatomorphs 1-3 form $\mathrm{O}-\mathrm{H} \cdots \mathrm{O}$ hydrogen bonds (HBs) with the oxygen atoms inside the complex, with $\mathrm{O} \cdots \mathrm{O}$ distances in the range 2.581(4) $\AA$ (in 1) - 3.057(3) $\AA$ (in 3) (Table 3, Figs. 4-6). In solvatomorph 1 the O6 water 
molecule is located on the twofold axis and is only partially occupied, but it forms hydrogen bonds with $\mathrm{O} 5$ and its symmetry related congener $\mathrm{O} 5^{1 \mathrm{i}}(1 \mathrm{i}: 1-\mathrm{x}, \mathrm{y}, 0.5-\mathrm{z})$ yielding a trimeric arrangement (Fig. 4).

In the solvatomorphs $\mathbf{2}$ and $\mathbf{3}$ molecules of the additional crystallization solvent are present, namely ethanol in $\mathbf{2}$ and isopropanol in $\mathbf{3}$. In both cases these alcohol solvate molecules are bonded to the water solvate molecule by $\mathrm{O}-\mathrm{H} \cdots \mathrm{O}$ hydrogen bonds (Table 3, Fig. 5, 6). We note that in 2 the ethanol solvate molecule suffers positional disorder of the O6 oxygen atom.

Table 3. Possible hydrogen bonds in 1-5 [ $\left[\AA,^{\circ}\right]$.

a) Complex 1

\begin{tabular}{|c|c|c|c|c|}
\hline $\mathrm{D}-\mathrm{H} \cdots \mathrm{A}$ & D-H & $\mathrm{H} \cdots \mathrm{A}$ & $\mathrm{D} \cdots \mathrm{A}$ & DHA \\
\hline $\mathrm{O} 5-\mathrm{H} 1 \mathrm{w} \cdots \mathrm{O} 3$ & $0.836(10)$ & $2.41(2)$ & $3.018(2)$ & $130(2)$ \\
\hline $\mathrm{O} 5-\mathrm{H} 1 \mathrm{w} \cdots \mathrm{O} 4$ & $0.836(10)$ & $2.217(12)$ & $3.021(2)$ & $161(3)$ \\
\hline $\mathrm{O} 5-\mathrm{H} 2 \mathrm{w} \cdots \mathrm{O} 2$ & $0.832(10)$ & $2.262(17)$ & $3.014(2)$ & $150(3)$ \\
\hline O6-H3W $\cdots$ O5 & $0.839(10)$ & $1.746(10)$ & $2.581(4)$ & $174(2)$ \\
\hline $\mathrm{C} 8-\mathrm{H} 8 \cdots \mathrm{O} 5^{1 \mathrm{i}}$ & 0.95 & 2.60 & $3.477(3)$ & 154 \\
\hline $\mathrm{C} 11-\mathrm{H} 11 \cdots \mathrm{O} 1^{1 \mathrm{ii}}$ & 0.95 & 2.57 & $3.492(3)$ & 164 \\
\hline $\mathrm{C} 13-\mathrm{H} 13 \cdots \mathrm{O}^{1 \mathrm{iii}}$ & 0.95 & 2.29 & $3.209(6)$ & 162 \\
\hline
\end{tabular}

Symmetry codes: 1i: x, 1-y, 1/2+z; 1ii: $1.5-x, y-1 / 2, z$; 1 iii : x-1/2, y-1/2, 1/2-z.

b) Complex 2 (1063)

\begin{tabular}{|c|c|c|c|c|}
\hline $\mathrm{D}-\mathrm{H} \cdots \mathrm{A}$ & D-H & $\mathrm{H} \cdots \mathrm{A}$ & $\mathrm{D} \cdots \mathrm{A}$ & DHA \\
\hline O5w-H5w1 $\cdots \mathrm{O} 1$ & $0.830(9)$ & $2.204(15)$ & $2.9026(16)$ & $142(2)$ \\
\hline $\mathrm{O} 5 \mathrm{w}-\mathrm{H} 5 \mathrm{w} 1 \cdots \mathrm{O} 2$ & $0.830(9)$ & $2.202(15)$ & $2.9252(14)$ & $146(2)$ \\
\hline $\mathrm{O} 5 \mathrm{w}-\mathrm{H} 5 \mathrm{w} 2 \cdots \mathrm{O} 3$ & $0.828(9)$ & $2.346(17)$ & $2.9718(15)$ & $133.0(17)$ \\
\hline $\mathrm{O} 5 \mathrm{w}-\mathrm{H} 5 \mathrm{w} 2 \cdots \mathrm{O} 4$ & $0.828(9)$ & $2.082(12)$ & $2.8468(16)$ & $154(2)$ \\
\hline 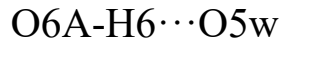 & $0.840(10)$ & $1.901(10)$ & $2.706(5)$ & $160(3)$ \\
\hline O6B-H6 $\cdots \mathrm{O} 5 \mathrm{w}$ & $0.841(10)$ & $1.901(10)$ & $2.702(9)$ & $159(3)$ \\
\hline $\mathrm{C} 8-\mathrm{H} 8 \cdots \mathrm{O}^{2} \mathrm{w}^{2 \mathrm{i}}$ & $0.952(17)$ & $2.554(17)$ & $3.2264(18)$ & $127.8(13)$ \\
\hline
\end{tabular}

Symmetry codes: 2i: -x, 1-y, 1-z; 2ii: x, 1+y, z;

c) Complex 3

\begin{tabular}{|c|c|c|c|c|}
\hline $\mathrm{D}-\mathrm{H} \cdots \mathrm{A}$ & D-H & $\mathrm{H} \cdots \mathrm{A}$ & $\mathrm{D} \cdots \mathrm{A}$ & DHA \\
\hline $\mathrm{O} 5 \mathrm{w}-\mathrm{H} 5 \mathrm{w} 1 \cdots \mathrm{O} 1$ & $0.835(10)$ & $2.078(19)$ & $2.781(3)$ & $141(3)$ \\
\hline $\mathrm{O} 5 \mathrm{w}-\mathrm{H} 5 \mathrm{w} 1 \cdots \mathrm{O} 2$ & $0.835(10)$ & $2.34(2)$ & $3.057(3)$ & $144(2)$ \\
\hline $\mathrm{O} 5 \mathrm{w}-\mathrm{H} 5 \mathrm{w} 2 \cdots \mathrm{O} 3$ & $0.840(10)$ & $2.37(2)$ & $3.057(3)$ & $139(3)$ \\
\hline
\end{tabular}




\begin{tabular}{|c|c|c|c|c|}
\hline $\mathrm{O} 5 \mathrm{w}-\mathrm{H} 5 \mathrm{w} 2 \cdots \mathrm{O} 4$ & $0.840(10)$ & $2.041(16)$ & $2.781(3)$ & $147(3)$ \\
\hline 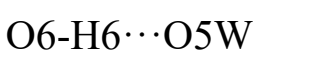 & $0.836(10)$ & $1.985(12)$ & $2.813(3)$ & $171(3)$ \\
\hline $\mathrm{C} 15-\mathrm{H} 15 \cdots \mathrm{O} \mathrm{WW}^{3 \mathrm{i}}$ & 0.95 & 2.56 & $3.472(4)$ & 161 \\
\hline
\end{tabular}

Symmetry codes: $3 \mathrm{i}: 0.5-\mathrm{x}, \mathrm{y}-0.5,0.5-\mathrm{z}$

\subsubsection{Intermolecular interactions in 1-3}

From the shape of the [Ni(o-van-en)] complex molecule it follows that it can participate only in weak hydrogen bonding interactions. The full interaction map (FIM) for 1 (Fig. 8) indicates that there are two acceptor regions (red) around the complex molecule, namely those corresponding to the $\mathrm{C} 8-\mathrm{H} 8$ and $\mathrm{C} 11-\mathrm{H} 11$ imine groups; both these imine groups are involved in weak $(\mathrm{N}=) \mathrm{C}-\mathrm{H} \cdots \mathrm{O}$ hydrogen bonds in $\mathbf{1}$ (Table 3a). These weak hydrogen bonds along with a weaker hydrogen bonding interaction involving the C13-H13 group leads to the formation of cavities within the supramolecular structure in which are enclosed the water solvate molecules (Fig. 9, Fig. S11). The packing forces also include $\pi$-stacking interactions between the C2-C7 aromatic ring and its congener, related by an inversion center, with distance $C \mathrm{~g} 1 \cdots C \mathrm{~g} 1^{1 \text { iv }}$ being 3.6221(12) A (1iv: 1-x, 1-y, 1-z). The same aromatic ring, on its opposite face, acts as an acceptor in a much weaker $\mathrm{C} 15^{1 \mathrm{v}}-\mathrm{H} 15^{1 \mathrm{v}} \cdots C \mathrm{~g} 1$ interaction $(1 \mathrm{v}$ : $0.5-\mathrm{x}, 1.5-\mathrm{y}, 0.5+\mathrm{z})$ with $\mathrm{H} 15^{1 \mathrm{v} \cdots} \mathrm{Cg} 1=2.84 \AA, \mathrm{C} 15^{1 \mathrm{v}} \cdots \mathrm{Cg} 1=3.614(2) \AA$ and $\mathrm{C} 15^{1 \mathrm{v}}-\mathrm{H} 15^{1 \mathrm{v}} \cdots \mathrm{Cg} 1=140^{\circ}$ (Fig. S12). We note that due to the packing arrangement the $\mathrm{Ni}(\mathrm{II})$ central atoms are well separated with a shortest $\mathrm{Ni} \cdots \mathrm{Ni}$ distance of $6.2080(4) \AA$. 


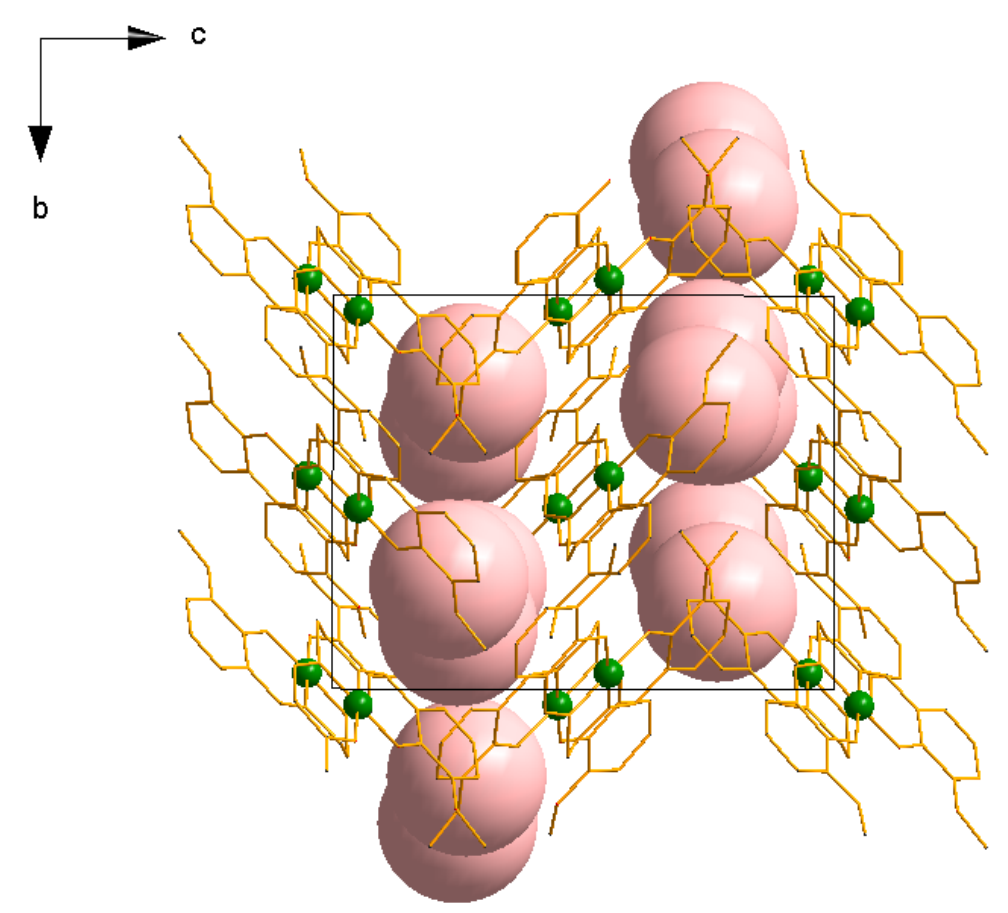

Figure 9 View of the packing in solvatomorph 1, showing the positions of the water solvate molecules (space filling fashion, pink spheres) in the formed cavities. The $\mathrm{Ni}$ (II) atoms are shown as green balls, the remaining atoms are displayed in wire mode.

In contrast, a typical feature of the packing for solvatomorphs $\mathbf{2}$ and $\mathbf{3}$ is the formation of centrosymmetric $[\mathrm{Ni}(\text { o-van-en })]_{2}$ dimers with short $\mathrm{Ni} \cdots \mathrm{Ni}$ distances, namely 3.3379(3) and 3.3712(6) $\AA$ for 2 and 3, respectively (Table 2, Fig. 10 and Fig. S13). Similar pairing of complex molecules, or even the formation of a chain-like arrangement, were reported for solvatomorphs 4 and 5 (Table 2) [15,16].

Previously it was suggested, that the observed short $\mathrm{Ni} \cdots \mathrm{Ni}$ distances may correspond to metal-metal interactions $[40,41]$. In order to verify this conjecture, theoretical calculations were done. In the model that was used to analyze the dimeric aggregates in $\mathbf{2}$ and $\mathbf{3}$, the total energy variation on forming a complex molecular system is decomposed as

$$
\Delta E_{\mathrm{tot}}=E^{\text {adduct }}-\sum_{i} E_{i}^{\text {fragment }}=\left(\Delta E_{\mathrm{els}}+\Delta E_{\mathrm{Ex}}\right)+\Delta E_{\mathrm{orb}}+\Delta E_{\mathrm{disp}}
$$

where $E_{\text {els }}$ is an electrostatic interaction term, normally negative if the two fragments are neutral; $E_{\mathrm{Ex}}$ is the exchange repulsion term, which comes from the Pauli repulsion effect and is invariably positive. For convenience, it is customary to combine these two terms as steric term ( $\left.E_{\text {steric }}\right) . E_{\text {orb }}$ in the above formula is the orbital interaction term, which arises from the mixing of occupied MOs and virtual MOs. For large molecules, it is necessary to include dispersion 
forces (van der Waals interaction) in the total interaction energy This was done using Grimme's DFT-D3 method to evaluate dispersion correction to interaction energy [42]. According to the previous calculations, we found for $\mathbf{2}$ and $\mathbf{3}$ :

\begin{tabular}{|l|l|l|l|l|}
\hline & $\Delta E_{\text {tot }}$ & $\Delta E_{\text {orb }}$ & $\Delta E_{\text {steric }}$ & $\Delta E_{\text {disp }}$ \\
\hline $\mathbf{2}$ & -204.17 & -84.78 & 28.52 & -147.90 \\
\hline $\mathbf{3}$ & -197.63 & -79.24 & 16.40 & -134.79 \\
\hline
\end{tabular}

\footnotetext{
*Energies in $\mathrm{kJ} / \mathrm{mol}$.
}

namely the total interaction energy between the Ni(II) complexes is $\sim-200 \mathrm{~kJ} / \mathrm{mol}$. The orbital interaction energy slightly stabilized the adducts, while the steric energy, which is the sum of electrostatic and exchange repulsion energy, destabilized the adducts by $\sim 16$ and $29 \mathrm{~kJ} / \mathrm{mol}$, respectively. However, the largest contribution to the stabilization energy comes from the dispersion interactions of the ligand systems ( $\sim 65 \%$ of the total interaction energy). Initial DFT calculations also provided Mayer bond order values, which for intermolecular atom-atom contacts are $<0.1$. We note that the calculations have shown that the estimated contribution from $\mathrm{Ni} \cdots \mathrm{Ni}$ interaction represent only about $11 \%$ of the whole attractive forces and that the main contribution comes from dispersion interactions between the ligands.

The presence of only weak dispersion interactions between the $[\mathrm{Ni}(\text { o-van-en })]_{2}$ dimers in 2 and 3, permits the accommodation of ethanol and isopropanol solvate molecules in the respective crystal structures (Table 3b and 3c, Figs. S14 and S15). In 2 the ethanol molecules are accommodated within parallel layers of the dimeric complex aggregates while in $\mathbf{3}$ the solvent isopropanol molecules are trapped in channels (Figs. 11 and 12). Thus, the resulting supramolecular structures in $\mathbf{2}$ and $\mathbf{3}$ enable diffusion across the quasi layers and channels and this may be the cause of the low stability of these crystals. A comparison of the densities (Table 1) shows that the crystal structure of the hydrate 1 is more compact $\left(1.546 \mathrm{~g} / \mathrm{cm}^{3}\right)$ than are the other two solvatomorphs $2\left(1.483 \mathrm{~g} / \mathrm{cm}^{3}\right)$ and $3\left(1.463 \mathrm{~g} / \mathrm{cm}^{3}\right)$. 

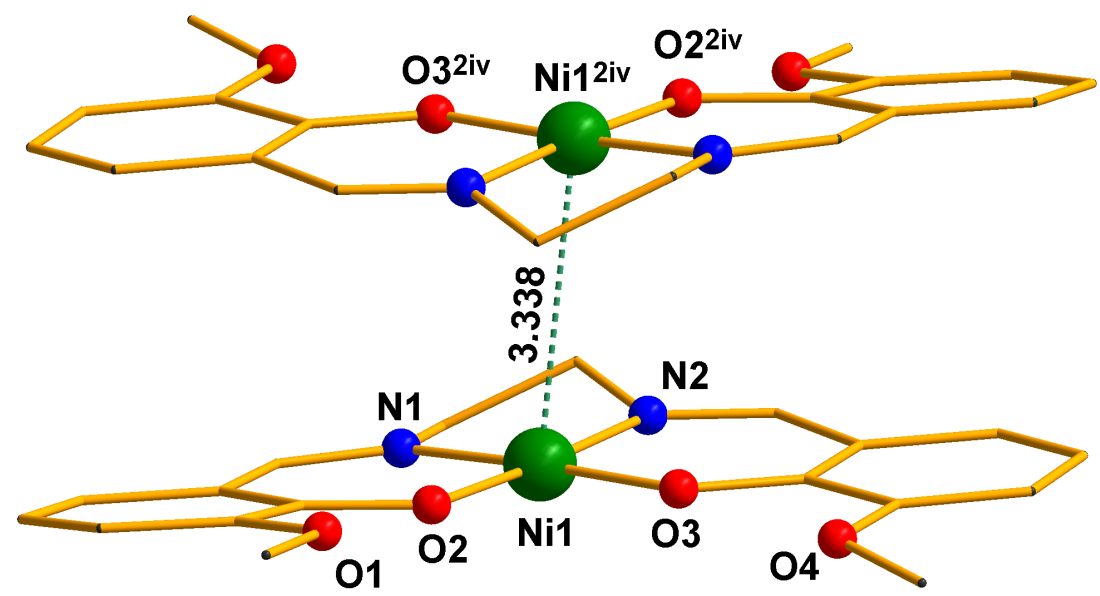

Figure 10 Formation of weakly bound dimer with $\mathrm{Ni} \cdots \mathrm{Ni}$ interaction (green dashed line) in 2. Symmetry code: 2iv: 1-x, 1-y, 1-z.

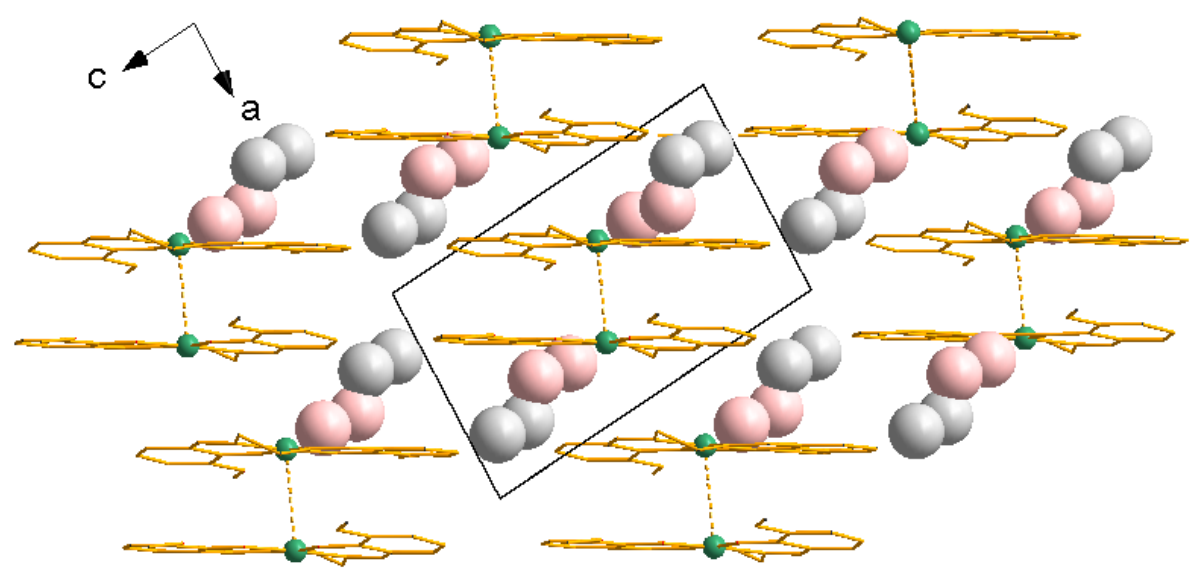

Figure 11 Packing of the complex molecules (wire model, nickel atoms as green balls) in 2 with solvent water and $E t \mathrm{OH}$ molecules ( $\mathrm{O}$ atoms are large pink balls, the carbon atoms in $E t \mathrm{OH}$ are large grey balls) located in the channels. Hydrogen atoms are omitted for clarity. 


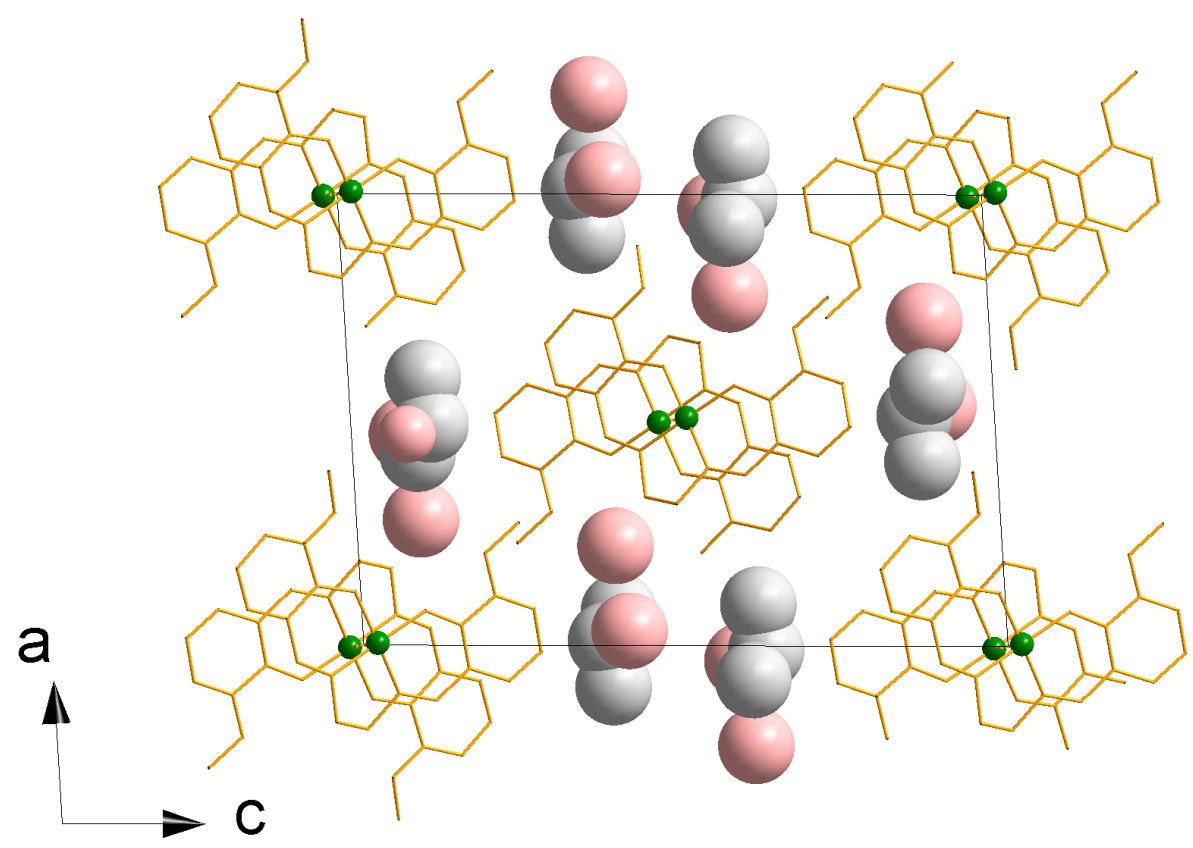

Figure 12 Packing of the complex molecules (wire model, nickel atoms as green balls) in 3 with solvent water and $i-\mathrm{PrOH}$ molecules (space filling) located in the channels $(\mathrm{O}$ atoms are large pink balls, the carbon atoms in $i-\mathrm{PrOH}$ are large grey balls). Hydrogen atoms are omitted for clarity.

\section{Conclusions}

Three different solvatomorphs were prepared by recrystallization of the crude nickel complex from various solvents, and were structurally characterized. Each solvatomorph is composed of [Ni(o-van-en)] complex molecules, a water solvate molecule placed near the larger compartment of the complex, and additional water (1), ethanol (2) or isopropanol (3) molecules which are linked by hydrogen bonds to the proximal water molecules. The water-containing solvatomorph (1) crystallizes with discrete, isolated complex molecules with water molecules trapped in the cavities, leading to the most compact structure. In contrast, in the solvatomorphs containing additional ethanol and isopropanol molecules, dimers of the complex molecules are formed, with short $\mathrm{Ni} \cdots \mathrm{Ni}$ separations, leading to less compact structures. Theoretical calculations have shown that the formation of dimers is mainly supported by attractive dispersion interactions between the ligands. Thermal analysis and temperature-dependent IR spectroscopy confirmed that dehydration is the first step in the decomposition of $\mathbf{1}$.

\section{Acknowledgements}

This work was supported by the Slovak grants APVV-18-0016 and VEGA (grant No. 1/0063/17). Funding from the Ministry of Science and Innovation (Spain) under grant 
PGC2018-093451-B-I00, from the European regional development fund (FEDER), and from the Diputación General de Aragón (Project M4, E11_20R) is gratefully acknowledged.

\section{Supplementary data}

CCDC 1983889 (3), 1983890 (2) and 1983891 (1) contain the supplementary crystallographic data for this paper. These data can be obtained free of charge via http://www.ccdc.cam.ac.uk/conts/retrieving.html, or from the Cambridge Crystallographic Data Centre, 12 Union Road, Cambridge CB2 1EZ, UK; fax: (+44) 1223-336-033; or e-mail: deposit@ccdc.cam.ac.uk.

\section{References}

[1] H.G. Brittain (Ed.), Polymorphism in Pharmaceutical Solids, Informa Healthcare USA, Inc., 2009.

[2] S. Boothroyd, A. Kerridge, A. Broo, D. Buttar, J. Anwar, Crystal Growth and Design 18(3) (2018) 1903-1908.

[3] A. Djemel, O. Stefanczyk, M. Marchivie, E. Trzop, E. Collet, C. Desplanches, R. Delimi, G. Chastanet, Chemistry - A Eur. J. 24 (55) (2018) 14760-14767.

[4] M. Cibian, G.S. Hanan, Chemistry - A Eur. J. 21(26) (2015) 9474-9481.

[5] B. Nowicka, M. Heczko, M. Rams, M. Reczyński, B. Gaweł, W. Nitek, B. Sieklucka, Eur. J. Inorg. Chem. 2017(1) 99-106.

[6] Y. Wang, Z. Liang, Journal of Crystal Growth 480 (2017) 18-27.

[7] S. Ramakrishnan, S.R. Yarraguntla, S.R. Peddireddy, S.L. Kanniah, V.K. Mudapaka, L.K. Shekhawat, S. Mahapatra, A.B. Mohammad, P. Vishweshwar, P.W. Stephens, Organic Process Research and Development 21 (10) (2017) 1478-1487.

[8] S. Aitipamula, P.S. Chow, R.B.H. Tan, Acta Crystallogr. B70(1) (2014) 54-62.

[9] J.M.F. Custodio, W.F. Vaz, M.R.C. de Castro, A. Bernardes, R.F. Navez, A.F. Moura, M.O. de Moraes, C.C. da Silva, F.T. Martins, C.N. Perez, H.B. Napolitano, J. Mol. Struct. 1175 (2019) 389-397.

[10] C.A. Gunawardana, C.B. Aakeröy, ChemComm 54 (2018)14047-14060.

[11] A. Vráblová, M. Tomás, L. R. Falvello, L. Dlháň, J. Titiš, J. Černák, R. Boča, Dalton Trans. 48 (2019) 13943-13952.

[12] M. Dolai, M. Ali, J. Titiš, R. Boča, Dalton Trans., 44 (2015)13242-13249. DOI: $10.1039 / \mathrm{c} 5 \mathrm{dt} 00960 \mathrm{j}$. 
[13] S. Sakamoto, T. Fujinami, K. Nishi, N. Matsumoto, N. Mochida, T. Ishida, Y. Sunatsuki, N. Re, Inorg. Chem, 52 (2013) 7218-7229. DOI: 10.1021/ic4008312.

[14] J. Wu, L. Zhao, P. Zhang, L. Zhang, M. Guo, J. Tang, Dalton Trans. 44 (2015) 11935 11942, DOI: $10.1039 / \mathrm{c} 5 \mathrm{dt} 01382 \mathrm{~h}$.

[15] Y.Y. Yu, Acta Cryst. E62 (2006) m948-m949.

[16] K. Ayikoé, R. J. Butcher, Y. Gultneh, Acta Cryst. E67 (2011) m948-m328.

[17] D. Cunningham, J. F. Gallagher, T. Higgins, P. McArdle, J. McGinley, M. O'Gara, J. Chem. Soc., Dalton Trans. (1993) 2183-2190.

[18] B.N. Ghose, J. Chem. Eng. Data, 29 (1984) 237.

[19] C.F. Macrae, P.R. Edgington, P. McCabe, E. Pidcock, G.P. Shields, R. Taylor, M. Towler, J. van de Streek, 39 (2006) J. Appl. Cryst. 453-457.

[20] A. Le Bail, H. Duroy, J.L. Fourquet, Mat. Res. Bull. 23 (1988) 447-452.

[21] V. Petříček, M. Dušek, L. Palatinus, Z. Kristallogr. 229(5) (2014) 345-352.

[22] R.H. Blessing, Acta Cryst. B51 (1995) 816-823.

[23] A. Altomare, G. Cascarano, C. Giacovazzo, A. Guagliardi, M. C. Burla, G. Polidori M. Camalli, J. Appl. Cryst. 27 (1994) 435.

[24] G.M. Sheldrick, Acta Cryst., C71 (2015) 3-8.

[25] M. Nardelli, J. Appl. Cryst., 28 (1995) 659-659.

[26] K. Brandenburg, H. Putz, (2008). Crystal Impact Diamond, Crystal and Molecular Structure Visualization, GbR, Postfach 1251, D-53002 Bonn, Germany.

[27] a) F. Neese, WIREs Comput. Mol. Sci. (2012) 2, 73; (b) F. Neese, ORCA - An Ab Initio, Density Functional and Semi-empirical Program Package, Version 4.2.1. 2019.

[28] T. Lu, F. Chen, J. Comp. Chem. (2012) 33, 580.

[29] C. R. Groom, I. J. Bruno, M. P. Lightfoot, S. C. Ward, Acta Cryst., B72 (2016) 171179.

[30] Z. Guo, L. Li, T. Xu, J. Li, D. Wang, Acta Cryst. E65 (2009) m1158-m1159.

[31] I. Correia, J. C. Pessoa, M. T. Duarte, M. F. Minas da Piedade, T. Jackush, T. Kiss, M. M. C. A. Castro, C. F. G. C. Geraldes, F. Avecilla, Eur. J. Inorg. Chem. (2005). 732744.

[32] A. Bartyzel, Inorg. Chim. Acta, 459 (2017) 103-112.

[33] K. Nakamoto, Infrared and Raman Spectra of Inorganic and Coordination Compounds, Part B: Applications in Coordination, Organometallic and Bioinorganic Chemistry, Wiley, New York, 1997. 
[34] D.-P. Li, Q. Wang, Y.-B. Xie, J. Zhang, Q.-Y. Lian, Y.-X. Li, Wuji Huaxue Xuebao (Chin.) (Chin. J. Inorg. Chem.), 34 (2018) 1547-1554.

[35] D.-X. Liu, S.-L. Li, X.-G. Cui, X.-Y. Li, Gaodeng Xuexiao Huaxue Xuebao (Chin.) (Chem. J. Chin. Univ. (Chinese Edition)), 14 (1993) 897.

[36] O. V. Amirkhanov, O. V. Moroz, K. O. Znovjyak, T. Yu. Sliva, L. V. Penkova, T. Yushchenko, L. Szyrwiel, I. S. Konovalova, V. V. Dyakonenko, O. V. Shishkin, V. M. Amirkhanov, Eur. J. Inorg. Chem. 23 (2014) 3720-3730.

[37] A. Finelli, N. Herault, A. Crochet, K. M. Fromm, Cryst. Growth Des. 18 (2018) 12151226.

[38] P. Bhowmik, S. Chatterjee, S. Chattopadhyay, Polyhedron, 63 (2013) 214-221.

[39] P.A. Wood, T.S.G. Olsson, J.C. Cole, S.J. Cottrell, N. Feeder, P.T.A. Galek, C.R. Groom, C. R. E. Pidcock, CrystEngComm. 15 (2013) 65-72.

[40] T. W. Thomas, A. E. Underhill, Chem. Soc. Rev. 1 (1972) 99-120.

[41] M. A. Siegler, M. Lutz, Cryst. Growth Des. 9 (2009) 1194-1200.

[42] S. Grimme, J. Antony, S. Ehrlich, H. Krieg, J. Chem. Phys. (2010) 132, 154104. 